\title{
Mechanistic coupling of social and biophysical models of water management through agent typologies
}

\author{
Kendra E. Kaiser ${ }^{1,2, *}$, Alejandro Flores ${ }^{1}$ and Vicken Hillis ${ }^{2}$ \\ ${ }^{1}$ Department of Geosciences, Boise State University, Boise, Idaho, USA \\ ${ }^{2}$ Human-Environment Systems, Boise State University, Boise, Idaho, USA \\ Correspondence to: kendrakaiser@boisestate.edu
}

August 29, 2018

THIS IS A NON-PEER REVIEWED PREPRINT SUBMITTED TO EarthArXiv

\section{Abstract}

M important due to expanding population, fundamental transitions in the uses of water, and changes in global and regional water cycling driven by climate change. Models that explicitly represent the coupled dynamics of biophysical and social components of water resource systems are challenging to design and implement, particularly given the complicated and cross-scale nature of water governance. Agent based models (ABMs) have emerged as a tool that can capture human decision-making and nested social hierarchies. The transferability of many agent-based models of water resource systems, however, is made difficult by the location-specific details of these models. The often ad-hoc nature of the design and implementation of these models also complicates integration of high fidelity sub-models that capture biophysical dynamics like surface-groundwater exchange and the influence of global markets for commodities that drive water use. A consistent, transferable description of the individuals, groups, and/or agencies that make decisions about water resources would significantly advance the rate at which ABMs of water resource systems can be developed, enhance their applicability across ranges of spatiotemporal scales, and aid in the synthesis and 
comparison of models across different sites. We outline here a framework to systematically identify the primary agents that influence the storage, redistribution, and use of water within a given system. Reviewing previous studies that apply ABMs to water resources, we propose eight water resources agent types that capture the operational roles that modify the water balance. This typology characterizes common actors in water management systems but can be modified to represent the particularities of specific systems when more detailed information about specific actors is available (e.g. social networks, demographics, learning and decision-making processes). Application of the proposed typologies will support the systematic design and development of transferable scaleable water resources ABMs and facilitate the dynamical coupling of social and biophysical process modeling. To demonstrate, we show the conceptual development of an ABM that describes the interaction of agents within the Boise River Basin in the western United States and illustrate how those agents interact with the biophysical system.

Keywords: water resources management, agent-based modeling, social-ecological systems, socio-hydrology

\section{Introduction}

Humans are affecting the availability and quality of water resources across scales ranging from local to global. The spatiotemporal distribution of freshwater influences and is influenced by human decisions about distribution of water across scales, creating a multiscale, dynamically coupled natural-human $(\mathrm{CNH})$ system. Globally, water withdrawals are increasing (2500 to $4000 \mathrm{~km}$ yr-1 from 1971-2010), but sectoral trends in water withdrawals vary across regions for a variety of reasons, including increasing water use efficiency, population growth and urbanization (Huang et al., 2018). Meanwhile, the availability of water impacts a range of societal decisions such as where to build and how to insure structures in floodplains, the type of crops to plant, water use restrictions in urban areas, trans-boundary water transfers, and infrastructure development (Dubbelboer, J., Nikolic, J., Jenkins, K., Hall, 2017, Ahmad and Prashar, 2010; Sehlke and Jacobson, 2005; Jeuland et al., 
2014). Globally, owing to the intensification of the global hydrologic cycle (Huntington et al., 2018) anthropogenic climate change has altered the frequency and intensity of precipitation and will continue to do so (Bates et al., 2008). Determining how climate change will affect this multiscale CNH system will be critical to assess potential adaptation strategies.

Hydrologic models that explicitly consider two-way interactions of humans and the biophysical environment has taken form as system dynamics models (Sehlke and Jacobson, 2005; Ma et al., 2007; Schenk et al., 2009) and hydro-economic models (Michelsen et al., 1999, Esteve et al., 2015, George et al. 2011). These models have emerged from a longstanding interest in integrated water resources management (Petak, 1980), which has promoted a holistic approach to water management that seeks to balance the competing needs of stakeholders within environmental constraints. Recognizing the importance of enhancing fundamental understanding of and the ability to model these systems, a growing subdiscipline of socio-hydrology, which focuses on the co-evolution of coupled human-water systems, has received increasing attention (Sivapalan et al., 2012). This subdiscipline can be distinguished from integrated water resources management insofar as it is explicitly exploring human responses to hydrologic events such as relocating or building levees after flooding (Di Baldassarre et al., 2013: Van Emmerik et al., 2014). Advances in the theoretical underpinnings of socio-hydrology have paralleled corresponding advances in social-ecological systems modeling, which presents a framework to determine the trajectories of $\mathrm{CNH}$ systems by integrating models of human behavior and decision-making with biophysical models of the environmental systems in which they are embedded (Ostrom, 2009).

Although these types of integrated models are becoming more common, there are ongoing challenges with respect to synthesis across systems, scaling across nested levels, and integration of various sub-models that represent key biophysical processes with high fidelity. Some of these challenges have been addressed within the hydrologic sciences through efforts such as the Community Surface Dynamics Modeling System (Peckham et al., 2013; Overeem et al., 2013), and other model coupling frameworks (Khan et al., 2017; Tidwell et al., 2001). Additionally, social theory has generally been underutilized in these integrated models, but agent based models (ABMs) are a 
promising tool to reflect the complex social interactions between individuals and organizations across scales.

ABMs are an increasingly popular class of models that are capable of explicitly capturing the dynamic feedbacks and cross-scale components of a CNH. Current ABMs focused on water management are often created in an ad-hoc fashion due to highly specific, place-based questions. This leads to a highly variable representation of individuals or hydrologic components across systems. Within the social sciences, various typologies have been created to abstract the recurrent or repetitive aspects of agents (Mckinney, 1950). Because typologies are not expected to be an exact representation of individuals, they can be a valuable heuristic tool and provide a basis for comparison across systems. These standardized classifications serve the model building enterprise by identifying the features of individuals influencing water resources and the associated hydrologic variables they affect, thus making modeling these systems more consistent and comparable.

Agent functional types (AFTs) have been proposed as an additional way to increase transparency of agent representations, and simplify model development (Arneth et al., 2014). Functional types define agent roles, attributes and behaviors, as well as social networks, imitation, and learning (Arneth et al., 2014). AFTs are analogous to plant functional types in that they can represent consistent individual responses to and influences on systems across large geographic extents (Arneth et al. 2014). Previous studies that have used AFTs as building blocks in ABMs have defined characteristics of various land owners, such as farmers (Valbuena et al., 2008; Dalolu et al., 2014) and forest owners (Blanco et al., 2015). AFTs have been used to analyze land use planning at the international scale (Blanco et al., 2015, 2017), determine how policy interventions affect spatial patterns of conservation practices (Dalolu et al., 2014), and have improved the clarity and flexibility of ABMs in ways that might increase the use of these models for planning and policy-making (Valbuena et al., 2008). For example, Blanco et al. (2017) found that the behavioral attributes of different forest owner types more significantly impacted profit and therefore land use dynamics than climate change alone. Importantly, these behavioral attributes influenced how different owner types managed their forests in response to societal demand for particular ecosystem services. In 
the context of water resources management, the use of AFTs could also lead to important insights about the emergent dynamics and path dependency of social-environment interactions. However, the hierarchical and cross-scale nature of coupled human-hydrological systems necessitates first creating a broader framework for capturing the diversity of water management actors.

Here we propose a typology for water resource management actors that can facilitate more transparent, transferable, and comparable ABMs of water management systems. Our agent typology is based upon a review of 42 published studies that apply ABMs to water resource systems. From these prior studies we identify common water resources agent types across systems, define their operational roles, associated input/output variables, and potential social interconnections. The typology is useful because the agent types allow expedited identification of agents to include in coupled water resources models, aid in the representation of nested social and institutional structures, simplify coupling with component sub-models, increase the transferability and synthesis of models across systems, and potentially enable development of regional scale $\mathrm{CNH}$ models of water resources. This broad agent typology would lay the foundation for more specific functional types to be developed within each type of agent (e.g. farmer and forest AFTs Valbuena et al. (2008); Blanco et al. (2015)). The remainder of the paper is organized as follows. First, we review current methods and challenges in modeling $\mathrm{CNH}$ systems. We then provide an overview of the literature review we conducted in developing this framework. We then outline the definitions of each agent type, associated biophysical and social interactions, and information that might influence modeled decision-making processes. And finally, we provide an example of how this framework would be used to develop an ABM of a coupled human-hydrologic system in an arid watershed in the Western US.

\section{Modeling Water Resources as a Coupled Natural-Human Sys-} tem

Analyzing and modeling water resources systems as explicitly CNH systems is receiving increasing attention in the literature. But methodologically these efforts are often isolated along traditional 
disciplinary boundaries that present unique strengths and important limitations (Table 1). For example, system dynamics models and optimization schemes have been the basis for many decisionsupport tools meant for participatory modeling and watershed management (e.g WEAP, Yates et al. 2005; RiverWare, Zagona et al. 2001). These are important tools that typically focus on applied scenarios. In contrast, socio-hydrology has focused on the co-evolution and behavior of coupled socio-hydro dynamical systems with the goal of advancing our fundamental understanding of how systems work and evolve. Hydro-economic modeling integrates economics with management options and infrastructure development and maintenance, and generally assumes that individuals have complete knowledge and make rational decisions (e.g. net benefit maximization, Harou et al. 2009). As an example of how the use of agent typologies in ABMs can simplify representations of individuals and their decision-making processes, we focus on system dynamics modeling as an overarching integrative tool for coupling agent based models (ABMs) with biophysical models.

System dynamics modeling is particularly suited for quantifying the complex feedbacks and relationships between sub-systems (for a comprehensive review see: Nikolic and Simonovic 2015 , Mirchi et al. 2012), but these often represent simplified versions of system components which do not necessarily include process-based components. Although institutions and individuals may be included in these systems models (e.g. Schenk et al. 2009; Rehan et al. 2013), they often lack depth and specificity in regard to social interactions and decision-making processes. Likewise, models that have been used in socio-hydrology have calibrated variables that are not directly linked to social theory and can omit important individual-level characteristics of decision making (e.g societal awareness Van Emmerik et al. 2014, psychological shock in Viglione et al. 2014). On the other hand, some models that represent realistic human actors simplify the hydrologic dynamics by using hypothetical or average hydrologic conditions (Woyessa et al., 2011; Cai and Xiong, 2017) or completely omit important processes (e.g. surface water-groundwater interactions). The challenge of representing each subsystem with a high degree of fidelity has promoted the use of multi-method models which use systems perspectives to combine process based models of the biophysical environment and agent based models that represent the socio-economic environment (Nikolic and Simonovic, 2015). 
Agent based models (ABMs) are increasingly being used for $\mathrm{CNH}$ system modeling because they can represent the dynamic feedbacks between human and environmental systems. Agents represent individuals, collections of individuals, groups, or organizations that make decisions based on responses to stimuli either in the environment or among other agents with whom they interact. Because agents may respond conditionally to combinations of stimuli, this allows ABMs to represent heterogeneous sets of agents that reflect the range of perceptions, beliefs and socio-economic status of the population of interest. Agents possess adaptive behavior and can utilize various decision-making mechanisms. ABMs allow us to identify cross-scale, dynamic, and emergent system behaviors (agents impact system, system influences agent behavior, Wilensky and Rand 2015). ABMs are valuable because they can represent network heterogeneity, local but complex interactions, and unequal distribution of information sources (Wilensky and Rand, 2015). This is a particularly useful tool for water resources management due to the ability to represent cross-scale components of systems and institutional hierarchies where higher representative units could be used in a nested approach (Rounsevell et al. 2012). For example, agricultural agents water rights could be represented as individuals, or as irrigation organizations which own water rights and ensure delivery to their users. Typologies can represent the operational roles of individuals or organizations and are the top level in a nested structure, where an agents' role(s) define how they interact with each other and the biophysical system. For water resources, a water agent typology would specifically identify how an agent influences the consumptive use or quality of water by directly or indirectly mediating the timing and distribution of water across the landscape. Although the individuals, and the exact structure of these relationships will change across systems, the roles and observational information used by water managers, or individual users will be relatively consistent (e.g. snow water equivalent, forecasted precipitation, groundwater levels, etc.). As such, classifying common types of individuals and institutions mediating the timing and magnitude of water flows will expedite and simplify coupling of models by identifying relevant input and output variables for ABMs.

The water agent typology that we develop here serves as a foundation for classifying agentfunctional types. Agent-functional types can synthesize heterogeneity in agent attributes and 
decision-making strategies. Land-use agent-functional types have been used in this way (Rounsevell et al., 2012), but the approach has not yet been applied to water management, in part because the first step is to develop a clear agent typology, as we produce here. AFTs characterize heterogeneity through agent attributes (e.g. socio-demographic or economic attributes, spatial data such as irrigated acres and crop type) and preference weights associated with agent objectives or desires which guide their decision-making (e.g. preferred management practices Blanco et al. (2015)). Decision-making strategies incorporate heterogeneity and uncertainty in how agents enact their role in the system and could include how they use available information and learn over time. These strategies can be represented by decision trees (heuristics), utility maximization, and bounded rationality, but the practice of including decision-making based on theory has been limited in the land use change ABM literature (Groeneveld et al. 2017). The use of optimization in water resource management is useful for identifying ideal outcomes given specified objectives and constraints. However, capturing the nuances and diversity (e.g., biases, stochasticity) in how decisions are made and propagate through coupled human-hydrologic systems is necessary to identify emergent properties and outcomes.

\section{A Classification of Water Resources Agent Types}

We conducted a literature review of water resources ABM papers, allowing us to systematically identify common water resources agents using both inductive and deductive approaches. Inductive analyses (such as clustering e.g. Fontaine and Rounsevell (2009)) might use national databases of socio-economic characteristics, or social surveys, while deductive reasoning uses a combination of cultural theory and expert opinion to create a more continuous multi-dimensional categorization (Talbot, 2009; Rounsevell et al., 2012). We used the ISI Web of Science to find water resources ABMs by using the following search terms: water + manage* / typ*; ABM + water; Grimm 2010 and Grimm 2006 with water + agent. Criteria for inclusion of studies into the review was that the ABM was used to assess some water resources issue (theoretical modeling experiments that were not based 
on a specific location were excluded) and with sufficient model description to characterize agents and associated roles. There were 39 papers included in the literature review, covering locations across the globe spanning the US (7), Europe (9), Asia (9), Africa (6), South America (4), the Middle East (3) and Canada (1). We documented the agents reported in each manuscript and grouped them by the characterization scheme provided by (Akhbari and Grigg, 2015). These agent types included urban/domestic, industrial, agricultural, regulator, environmental, hydropower, and recreation.

Within each agent type we documented associated roles used in each model (Table 2). These operational roles encapsulate the mechanisms by which each agent type influences water quality or quantity in the system. After reviewing the roles of each agent type we modified the Akhbari and Grigg, 2015) classification scheme in regard to three of the agent types. First, rather than having a functional type that specifically represents hydropower generation we broadened the scope to include all dam managers. This enables representation of individual dam operation objectives through attributes of a given dam manager. Secondly, we grouped environmental and recreation agents into an interest group agent. These various agents have a specific role of communicating a range of desires from constituents to regulatory agents. We also added two new agent types, utilities and economic agents because they were used in numerous ABMs and represent specific roles further defined in section 3. Our final agent types include: agriculture, regulatory, domestic, industrial/commercial, utilities, interest groups, reservoir managers, and economic agents.

The most common agent types found in the literature were irrigators, regulators, and domestic users, present in $32 \%, 21 \%$ and $16 \%$ of papers respectively (Figure 1). In the following sections we define the role of each agent type, specify at what scale and at which point(s) in the biophysical system they act, how and to what extent they communicate with other agents (Figure 2), and identify the type of information they use in decision-making and potential attributes that might influence those decisions. We then highlight research gaps and future work that could build on research in the literature review. 


\subsection{Agriculture}

The role of the agricultural agent is to withdraw water from the system, distribute and apply it to the landscape through irrigation.

These agents main role is to withdraw water from the system either from surface or groundwater for irrigation purposes (Table 2). They can also create and maintain structures that transport water to agricultural areas (e.g. canals), add new groundwater wells and irrigation systems (Becu et al., 2003), buy and import water (Barthel et al., 2008), and adopt innovations such as irrigation or pumping technology that directly impact their consumption of water (Holtz and Pahl-Wostl, 2012). The agricultural domain is one of the most commonly used functional types in water resources ABMs (Figure 1).

\subsubsection{Biophysical Interactions}

Agricultural agents operate across scales, representing individual farmers or irrigation districts. Higher-level organizations, such as water districts can control the distribution of water to canals, ditches, pumps and facilities diverting water (IDWR, 2018). Agricultural agents have a direct influence on stocks and flows of water; at the largest scale they divert water from rivers into extensive canals which results in evaporative losses, and leakage into the shallow groundwater table. At the individual scale, agents determine how many acres to irrigate, and the quantity and source of water to use, thereby effecting evapotranspiration and return flows across large areas. Their role in the biophysical system also has significant impacts on carbon and nitrogen cycling and associated water and soil quality.

\subsubsection{Social Interactions}

Agricultural agents make decisions using information from a variety of sources, including family members, personal expertise, farmers' associations, neighbors, research institutes, private consultants, or the internet (Karali et al., 2013, Barbalios et al., 2013). Their social networks can influence individual interactions and knowledge sharing about irrigation technologies and conservation prac- 
tices. Farmers and irrigation districts can share information regarding timing and quantity of water to deliver. Irrigation districts can be the interface between farmers and the individual who manages water distribution who is often overseen by the regulator agent (Becu et al., 2003 ; Berger et al. 2007: IDWR, 2018).

\subsubsection{Decision - making}

Agricultural decisions are a function of individual incentives, transaction costs, institutional rules, and interactions between local users and higher-level irrigation agents. As such, both individual decision-making and social dynamics influence the use and distribution of water in a system as impacted by agricultural agents. Agricultural agent decision-making would then be based on values related to profit, history, new technology, and loss aversion (Table 3). For example, profit would be based on forecasted yield of a given crop, and history would characterize decisions made in the previous time steps (e.g. they grow three crops in rotation). Adaptation of new technology could be based on information exchange with other agricultural agents within some range of their social network and socio-economic status. Loss aversion would characterize how much risk an agent is willing to take, this could be a function of predicted weather or market variability.

\subsubsection{Insights and future work}

In the papers we reviewed, agricultural agents were the type most commonly represented by multiple instances within one model. Rather than using general agricultural agents, many papers represented the heterogeneity of these agents using specific attributes, such as source of water Kock, 2008; Van Oel et al., 2010, 2012), or type of farming (Bah et al., 2006; Souza Filho et al., 2008; Farolfi et al., 2010; Espinasse, 2005). Additional attributes include socio-economic factors, farming experience, farm size (Cai and Xiong, 2017; Yuan et al., 2017), on-farm non-ag activities, membership in conservation organization (Giuliani and Castelletti, 2013), number of wells (Barthel et al., 2008), crop choice and planting date, labor force allocation, farm business structure (Holtz and Pahl-wostl, 2005), entrepreneurship and dependence on irrigation resource (Cai and Xiong, 2017). Some of 
these attributes can be combined and classified into specific types of farming practices that are aligned with the original AFT concept as defined by (Rounsevell et al., 2012) and (Arneth et al., 2014). Farming practices have been aggregated as profit oriented, multifunctionalist, traditional, hobbyist or part-time, and business oriented (Holtz and Pahl-Wostl, 2012; Karali et al., 2013).

\section{$3.2 \quad$ Regulator}

Regulators are agents that create or enforce local, state, or federal policies. This agent encompasses both policy makers who create rules and regulations and the administrators that enforce them.

Regulators allocate water and permits (e.g. pertaining to water quality), record violations, enforce associated penalties, and can develop large-scale infrastructure (Table 2, Noël and Cai (2017); Tidwell et al. (2012); Bakarji et al. (2017); Berglund (2012); Kock (2008); Berger et al. (2007)). They can affect all (or a subset of) actors within their regulatory boundaries (federal, state, council of governments, county, municipality), and actions will generally occur at the organizational/ institutional level, although decisions can be influenced by individual biases. Governance is defined broadly as means for society to make collective decisions and actions for managing common pool resources (Chaffin et al., 2016), the regulatory agent is encompassing formal governance, while informal governance might be better represented by individual agent types (e.g. home owners associations would fall under the Domestic agent).

\subsubsection{Biophysical Interactions}

Regulatory agents do not directly move or store water in the biophysical system, rather they influence the system via the other agents they interact with. Regulators can have access to relevant data about the system such as snow water equivalent in the snowpack or forecasted streamflow or have indirect access to this knowledge via experts with whom they communicate. They also have knowledge pertaining to past allocation rules, water rights, and water quality data Akhbari and Grigg, 2015). 


\subsubsection{Social Interactions}

The regulatory agent is socially connected to most other agents in the system because they are monitoring the state of the environmental system and whether other agents actions fall within the established rules and standards. They can communicate to other agents about the state of the system through direct communication, or through other means such as media outlets (Bakarji et al. 2017). They can then enforce their regulatory actions through fees and penalties. The regulatory agent receives information about opinions and needs of other agents within their jurisdiction mainly via the interest group agent.

\subsubsection{Decision-making}

These agents make decisions based on established regulations, public opinion, profit, and perception of environmental conditions (Table 3). These decisions are a function of the regulators attributes which might include the spatial extent of their regulatory boundaries and the objectives of the institution they represent. Types of regulation can be represented as command and control (e.g. zoning and strategic planning), or incentive-based. The rules and regulations could be parameterized based on constrained optimization problems (Bakarji et al., 2017), or actual regulations obtained from local, state, or federal agencies. Public opinion could be a component of their decision making through the influence of interest groups, and profit would capture the influence of fees/ fines and financial resources. Their perception of environmental conditions could be based on data they obtain from the system, or indirect information that they receive through other individuals Akhbari and Grigg, 2015).

\subsubsection{Insights and future work}

Adaptive management literature suggests that decentralized governance is ideal for sustainable resource management, but governance is complex and some key management decisions can irrevocably alter future system configuration (e.g. systems are path dependent). They can be represented by hierarchical, multi-level networks (Kenbeek et al., 2016). Representation of actual network structure 
is important for evaluating adaptation, coordination and conflict resolution (Chaffin et al., 2016, Newig et al., 2010, Rathwell and Peterson, 2012) but was not represented in the reviewed literature. Tribal water rights, for example, are often legally mandated at the state or federal level, while management decisions might also be influenced by interest groups that represent them.

\subsection{Domestic}

Domestic agents consume water for indoor and outdoor residential uses.

The main role of domestic water users is to consume water for indoor and outdoor residential uses (Table 2). They are often modeled at the individual or household level, which enables their use in modeling population growth and expansion preferences (Zellner, 2007; Berglund, 2012; Nikolic and Simonovic, 2015). They can also implement various water saving strategies, which occur at the household level, such as installation of water saving appliances or adoption of water reuse programs (Elhay et al., 2016; Soboll et al., 2011).

\subsubsection{Biophysical Interactions}

Domestic water users directly remove water from the system both for consumptive and nonconsumptive use. They generally receive water from the system via the water utilities, or from individual groundwater wells. Indoor water uses return water to the system via wastewater treatment plants or individual septic systems, which in turn affects the local water quality. Outdoor water uses can result in changes to evapotranspiration, shallow groundwater recharge, and water quality.

\subsubsection{Social Interactions}

Domestic agents receive secondary information about the system through friends, family, and neighbors, as well as news and media sources (e.g. Elhay et al. 2016 ; Barthel et al. 2008). This information generally pertains to the hydrologic state of the system (drought or flood stage), water reduction goals, or limits imposed by the regulatory agents or water utilities (Koutiva and

Makropoulos, 2016). Adaptations taken by domestic water users can be modeled as a function of 
social networks where their decisions are based on neighbors adoption of conservation practices (Barthel et al., 2008). Explicitly representing individual decision-making, allows for diffusion of actions and emergent responses to the state of the system (e.g. water use reduction during drought).

\subsubsection{Decision-making}

Attributes of domestic water users can reflect socioeconomic factors (Akhbari and Grigg, 2015), but household and lot size (Tidwell et al., 2012) are the primary attributes used to characterize variability within this population. These can help parameterize water use patterns and adoption of water saving strategies. For example, households with large lots sizes will likely use more water for outdoor use, and social networks might influence the likelihood of an agent adopting water conservation strategies. Their decisions would be based on minimizing costs, history of previous actions, new technology, and both local and global social influences (Table 3).

\subsubsection{Insights and future work}

Characterizing domestic water users is often aided by publicly available information such as census data. Further examination into how social networks and perceptions of risk influence individual decision-making will certainly create more robust models of how these agents influence the hydrologic cycle.

\subsection{Industrial/ Commercial}

Industrial agents use water for processes such as fabricating, cooling, washing, processing, diluting or transporting a product (Dieter et al., 2018).

The role of industrial agents is to extract and discharge water, treat discharge, and trade water quality permits (Table 2, Berglund (2012); Zellner (2007)). These agents operate at the organizational scale, and decisions are often based on allocated permits (Nikolic and Simonovic, 2015, Akhbari and Grigg, 2015). They have all the relevant operating information about their facility, namely the amount of water entering and leaving their property, past allocation rules, water 
rights, and assimilative capacity of the system (Akhbari and Grigg, 2015).

\subsubsection{Biophysical Interactions}

Depending on the industrial agents source of water and location of discharge, they can directly impact instream flows and downstream water quality, or groundwater levels and quality.

\subsubsection{Social Interactions}

These agents communicate with downstream water users when they surpass water quality standards and with other industrial agents or regulatory agents to buy additional water quality permits. The attributes of this agent will be dominated by characteristics of the industrial process they are performing, and their associated water rights, or pollution permits (Nikolic and Simonovic, 2015 , Akhbari and Grigg, 2015).

\subsubsection{Decision-making}

Industrial agent decisions would be based on minimizing costs, which are a function of regulatory restrictions and fees in addition to demand for their good/ service, itself a function of local and global markets (Table 3). They would also operate based on previous operating procedures, with adaptation of new technologies being a function of social pressures and profit margins. Hypothetically they could also make decisions to minimize environmental impacts, but this would largely be a function of social pressures (aggregated by the interest group agent) and regulatory mandates.

\subsubsection{Insights and future work}

In our review we found only 5 papers that included industrial or commercial agents. Thermoelectricpower generation in the U.S. accounts for $41 \%$ of freshwater withdraws (Dieter et al., 2018). Although consumptive use is relatively small, incorporating these facilities in modeling efforts will be critical to modeling across the food-energy-nexus Kimmell and Veil, 2009, Tidwell et al., 2013, US Department of Energy, 2014). Given the scale of their influence on water resources, incorporating the actions of 
industrial activities in ABMs could provide additional insight about overall system function.

\subsection{Water Utilities}

Water utilities are public or privately owned organizations that obtain, treat, and deliver water to service connections.

In order to provide uninterrupted supply of safe, pressurized drinking water, utilities control large distribution systems, construct and maintain infrastructure, and identify new water resources (IDWR, 2018). These agents generally function at the organizational level. The most common way water utilities have been included in water resources ABMs is in implementing and enforcing water use restrictions (Table 2).

\subsubsection{Biophysical Interactions}

Water utilities directly affect stores and fluxes of water in biophysical models by withdrawing groundwater or surface water, and by treating wastewater and return it to a given river reach. They can also indirectly impact fluxes of water through water restrictions and rate structures which influence how much water domestic agents use. Water supply companies have direct access to current and future water use needs (e.g. total domestic demand now, and in the future with urban growth), which allows them to make decisions regarding the development of new infrastructure or implementing water use restrictions.

\subsubsection{Social Interactions}

They communicate conservation goals and water use restrictions to their users and can relay warnings or use restrictions regarding drinking water quality (Barthel et al., 2010). They might have more direct communication with regulatory agents and serve as an intermediary between them and their customer base. They can also mitigate issues by using reserves without informing the customer base (Barthel et al., 2008). 


\subsubsection{Decision-making}

Water utilities will make their decisions based on profit margins, history, growth/development projections, regulatory mandates / operational targets, and technological advances (Table 3). Their profit margins will determine the scale and timing of infrastructure improvements and expansions. The decision to do this can be a function of growth projections (which could be information supplied by the economic agent) and expected changes in water supply (e.g. climate change projections). They will be constrained by the regulatory agent to provide some level of water quality, and quantity in their service area. Technological advances might be adapted based on demand or social pressures.

\subsubsection{Insights and future work}

Attributes of water utilities include information on their customer base (number of people they serve, and the timing of that service), characteristics of the water source (supply area, withdraw limits), and attributes of the organization itself such as ownership and management (Baietti et al., 2006), the affiliated water supply companies and transboundary transfers (Barthel et al., 2010). These attributes could be used to designate different functional types for water utilities. For example, public water systems are designated based on population served and duration of service, while other ownership types include municipal, investor-owned, conservancy district, cooperative, not-for-profit, and regional water districts. The variability in utilities could impact operating procedures, growth, and water pricing. This highlights the appeal of creating functional types, they can capture and synthesize much of this variation in a way that makes model building more tractable.

\subsection{Interest groups}

The interest group agent includes individuals or organizations that use various mechanisms to impart behavioral change in the system.

The role of interest group agents is to impart influence in the system via education and outreach to influence public opinion, or through advocating for government and industry to change regulations and policies (Table 2). They can represent environmental NGOs, tribal communities, recreational 
users, the agricultural sector, or taxpayers in general (e.g. (Thoyer et al., 2001)). As such, they might operate at the organizational scale, but they can influence individuals within other agent types or at the institutional/organizational level in regard to policies and regulation as dictated by the regulatory agent.

\subsubsection{Biophysical Interactions}

Interest groups do not directly change stores or fluxes of water, but they do monitor the biophysical environment in regard to the interests of their constituents. Influence on the biophysical system is most likely to occur through exerting influence on other functional types through social interactions.

\subsubsection{Social Interactions}

The influence of interest groups is imparted through a variety of social mechanisms. These agents have information on rules and regulations set by regulatory agents, other agents compliance to those rules, and satisfaction of the stakeholders they represent. They can serve as a watchdog where they help to enforce agreements monitor compliance, or prevent illegal activities, and file lawsuits, or alternatively, as an enabler where they provide resources for capacity building, facilitate network building and funding acquisition (Crosman, 2013). These groups can also can represent an expert role in the system through their work to use science to inform and guide management decisions, or as a mediator between regulatory agents and others in the system (Islami, 2017). Interest groups can also play a manager role in the system through hands-on management of restoration projects or conservation easements or reserves (e.g. land trusts management partnerships, strategic planning tools, acquisition and zoning). Finally, they can play an important role in disseminating information to other actors.

\subsubsection{Decision-making}

Interest groups will decide to communicate with other agents based on their social network/capital, the environmental state of the system, history of interactions, and new technology (Table 3). These 
agents may be programmed to monitor some measure of agent satisfaction for collections of other agents assigned as their constituents, and report the aggregate satisfaction to regulating agents. For instance, an interest group agent might keep track of how often industrial agents cannot use their allotted water right and report the total amount of unsatisfied demand to a Water Utility agent that may, in turn, develop new water resources to satisfy this unmet demand. Or they might monitor how many times an agent has violated terms of water quality permits and report them to the regulator agent. Their previous interactions will influence current decisions (e.g. continued pressure for instream flows for fish). They may monitor new technological advances and can promote those options to other agents in the system to meet their mission.

\subsubsection{Insights and future work}

Interest groups represent a heterogeneous set of organizations. Identifying the AFTs associated with these organizations could help classify their different objectives and the ways in which they influence a CNH system.

\subsection{Reservoir Management}

Reservoir management agents represent reservoir operations which control the timing and amount of reservoir outflow.

Rather than using hydropower as an independent agent (which was common in the literature review: Akhbari and Grigg 2015, Kock 2008, Giuliani and Castelletti 2013), we posit that a reservoir manager has a unique role in water management which could represent the interest and knowledge of agents from private, federal, or state-owned reservoirs (Table 2).

\subsubsection{Biophysical Interactions}

Reservoir managers have the largest direct role in water management by determining reservoir outflow. This sets the downstream discharge, as well as the areal extent of the reservoir which impacts total evaporation and local recharge (through groundwater-surface water interactions). 


\subsubsection{Social Interactions}

Reservoir release schedules are optimized for specific objectives such as flood control, late season irrigation releases, or consistency in hydropower production (BPA et al. 2001). This requires coordination between federal, state, and private dam owners in order to provide these downstream services. For example, the Coordinated Columbia River system includes run-of-river dams, storage dams, hydropower generation, and multi-purpose facilities which function based on the Pacific Northwest Coordination Agreement, the Columbia River Treaty, federal flood control statutes, and various environmental regulations (BPA et al. 2001). This will result in frequent interactions with the regulatory agent who, might be providing the rules and regulations for reservoir management (e.g. Army Corps of Engineers Water Control Manuals). Although reservoir managers might be represented as an individual, they are reflecting institutional/elective procedures (see Saqalli et al. 2010)

\subsubsection{Decision-making}

Reservoir attributes that impact agent decision-making include the type of dam (e.g. run of river), total capacity (live/dead storage), number of turbines, energy demand and pricing (Akhbari and Grigg, 2015), and potential exposure to litigation (Kock, 2008). Cai et al. (2011) represent multipurpose reservoirs (water supply, flood control, and hydropower generation) with behavior rules based on operational targets (from regulatory agent) and maximization of hydropower generation. Their decisions will also be based on historical operations of the dam and profit margins (Table 3).

\subsubsection{Insights and future work}

Interestingly, decision-making regarding dam operations were not represented often in the reviewed ABM literature. For example, Van Oel et al. (2012) use an empirical data set on reservoir releases instead of implementing autonomous decision-making. Representing individual decision-making in reservoir operations is an important source of variability in these systems because operational targets only serve as a guide and are not codified law (US Army Corps of Engineers, 1985). In the 
U.S., Patterson and Doyle (2018) determined the occurrence and magnitude of departures from operational targets by comparing the rule curves from water control manuals to actual reservoir outflow. This type of dataset could be particularly valuable for validating ABMs that aim to capture this variability.

\subsection{Economic Institutions}

Economic agents manage capital invested in the water sector to either reduce water-related risks or increase capital gains from water-related investments.

Water supply intrinsically affects, and is affected by, economics. The role of economic agents is to manage capital invested in the water sector, and provide information to other agents about the economic state of the system (Table 2). Economic agents can also create private and public water markets, sell insurance (e.g. flood), or oversee water banking (Ghosh et al., 2014), taxes, subsidies, infrastructure investments (Dadson et al., 2017), fines, transaction costs, and conservation rate structures (Michelsen et al., 1999; Mulligan et al., 2014).

\subsubsection{Biophysical Interactions}

Economic agents do not have any direct influence on stocks and flows of water. However, they potentially exert strong indirect influences on fluxes of water because they may preferentially provide financing and access to capital for water management technologies that are likely involve less risk. In doing so they convey exogenous signals from regional and global markets to actors within the local model. As such, they may significantly constrain the decisions of other agents, particularly the Agricultural, Municipal, Domestic, and Commercial/Industrial agents.

\subsubsection{Social Interactions}

Water demand is variable over time due to population and business growth, while costs are variable due to the source and availability of water. Therefore, evaluating supply and demand of water can be instrumental in assessing water management plans, options for urban growth, risk pooling/shifting 
(Baum et al. 2018), and both industrial and agricultural business strategies. Economic agents can interact with any other agent, either directly (e.g. providing flood insurance, (Dubbelboer, J., Nikolic, J., Jenkins, K., Hall, 2017)) or indirectly (characterizing the economic state of the system, or household water costs Rehan et al. 2013). These decisions create dynamic interactions between economic growth and things such as infrastructure investments and associated changes in risk from hazards such as flooding (Dadson et al., 2017).

\subsubsection{Decision-making}

Economic agents could be parameterized based on local and/global market influences and social capital (Table 3). They would be aggregating information on these markets and transmitting this information to other agents, while the likelihood of adopting a new market strategy could also be a function of social interest as aggregated by the interest group agent. Attributes of the economic institutions will reflect the ways in which they either infuse, restrict, or amplify financial benefits of various management strategies. In Dadson et al. (2017) their conceptual model describing investment is based on the actual hydrologic state, and the perception of the hydrologic state, in addition to potential technology or policy driven reduction in water use efficiency. This would require both hydrologic predictions and a stochastic component that could be driven by an ABM. The economic agent could also act as a simple interface to a more complicated economic, or hydro-economic model, which sets the rules by which other agents make decisions based off of (e.g. market prices for crops, labor costs etc., Schlüter et al. 2009).

\subsubsection{Insights and future work}

There has been extensive research that aims at assessing the value of ecosystem services (e.g. Huber-Stearns et al. 2017, Mavrommati et al. 2016) in order to quantify outcomes that are omitted by conventional economic valuation. Agent based models could be a particularly valuable tool for incorporating individual values and their decisions into economic analyses which often make assumptions about the rationality of actors and availability of information (optimal control models, 
Mulligan et al. 2014).

\section{Example of conceptual model development using agent types}

Water scarcity is of particular importance in the western United States where flood control volumes in reservoirs is needed to mediate flood risk from annual snowmelt, but water storage is necessary for irrigation water demands later in the growing season. This example explores whether and how a system of interacting users with various objectives can simultaneously prevent snowmelt driven flooding, maintain a minimum stream flow for fish, and provide water for downstream water rights holders. Here, we use this common scenario to show how agent types interact with one another and with the biophysical environment (Figure 3). This conceptual outline illustrates the value of a general typology and provides other modelers with a useful starting point in formal model construction.

On annual timescales the regulator agent creates and enforces rules for the system and coordinates with the reservoir manager. The factors influencing reservoir operations will be based on the dam objectives (e.g. flood control, storage, and maintaining environmental flows) and the individual reservoir manager. Details on the individual controlling reservoir outflows could include risk tolerance, hydrologic knowledge in the form of access to data on snow water equivalent or predicted streamflows, memory, and/or social connections with other agents that are dependent on in-stream flows. In the Boise River Basin, once the flood control season is over, decisions regarding the release of water from the dam are determined by the water master (agricultural agent) who determines how much flow is needed to fulfill water rights. This is based on communication with individual farmers within the irrigation district(s), but has to fall within the regulatory statutes associated with their water rights (thereby having oversight from the regulatory agent). Farmers within the irrigation district determine how much water they need based on the number of acres they are irrigating and crop water demand, both of which would have been determined at an earlier time step as a function of agricultural markets and other economic factors (economic agent), and potentially 
interactions/communication with other agricultural agents. This series of decisions by the individual farmer results in withdrawals from the canal $\left(q_{c}\right)$, a water flux onto their fields via irrigation $\left(P_{\text {eff }}\right)$, increased evapotranspiration $(E T)$ due to decreasing water limitation, and potentially shallow groundwater recharge or surface overland flow. Return flows, or surface water-groundwater exchange between the irrigated land and the canal can then be calculated $\left(R_{f}\right)$.

The utility of the agent typology is that we can represent the influential agents with or without data on individuals, thus bridging theoretical and empirical approaches. By reconciling these approaches, we are able to create a theoretical landscape and populate it with agents using only the most relevant data. For example, we could collect data to parameterize reservoir agents, or we could represent them using just the reservoir rule curves with a variety of parameterizations for their biases. This simplification also enables clear identification of critical agents in the system. In this example, the water master is a critical link between the agricultural agents decisions and reservoir management. Without that social interaction, there would be no way to aptly capture reservoir discharge after the flood control season. The roles associated with each agent allows for easy identification of which hydrological variables they affect or respond to. For example, precipitation could be applied to the basin that the reservoir manager is responding to, or it could be the effective precipitation that the agricultural agents apply to their fields. This simplifies our ability to transfer the model to another basin or combine with other basins to create a regional model.

\section{Discussion}

A standard set of agent types affecting water resources will benefit the increasingly frequent efforts to model water resources from a $\mathrm{CNH}$ systems perspective. Current models often define individuals in a given system in an ad-hoc fashion, which limits the clarity and transferability of models across systems and scales. The proposed agent typology will aid in future model development by explicitly defining the roles of agents and the biophysical pools and fluxes their decisions influence. This will also aid multi-method modeling approaches or the integration of submodels which could alleviate 
some of the imbalances in process detail of social and biophysical components of the system. Using the same set of agents across water resources ABMs could result in transferable models that can be scaled from individual basins to entire regions with multiple interacting management districts. Consistent classification of actors will also support comparison of models and modeling results from various CNH systems.

\subsection{Findings from Literature Review}

Although there were commonly used agent types in our literature review, such as agricultural and domestic water users, there were a few agent types not represented by the previous classification scheme suggested by Akhbari and Grigg (2015). These agents were grouped into the new agent types that we have defined as: interest groups, economic institutions, and reservoir managers. The only agents found in the literature that we omitted from the classification scheme were representing physical pools or fluxes (Cai et al., 2011; Bithell and Brasington, 2009), or behavioral differences (Farhadi et al., 2016). We believe it is critically important that future ABMs use hydrologic models (rather than agents) to represent those pools and fluxes in order to capture potential emergent dynamics within the natural system.

Interestingly, although reservoirs represent large pools and fluxes of water, they are not commonly incorporated into current water resources ABMs. This could be due to the extensive use of system dynamics models to optimize reservoir operations (Ahmad and Simonovic, 2004, 2000; King et al. 2017)), or other operational models for reservoir system management (RiverWare Zagona et al. 2001, WRAP Wurbs 2005), but nonetheless highlights an avenue of research that has not been thoroughly explored using ABMs (but see Becu et al. 2003; Jeuland et al. 2014). Reservoir managers do have to follow predetermined guidelines and rule curves, but they are influenced by their understanding of the system, individual biases, and state of the system (Patterson and Doyle, 2018), which was not explored by the reviewed papers. Although regulatory agents are used in many of the reviewed ABMs, there were limited examples of how various governance structures, or regulatory mechanisms affected the hydrologic state of the system (but see Rathwell and Peterson 2012). Likewise, economic 
agents were not commonly used in the reviewed ABMs, potentially because of the popularity of hydro-economic modeling (see Harou et al. 2009 for a review) which is grounded in the optimization methods of traditional economics which does not generally include variable information availability, or non-rational decision-making. Agents that fall under interest groups were variable across the literature, but we have identified that their main mechanism of affecting water resources is through communication with their associated constituents and regulatory agents.

\subsection{Limitations of the typology approach and future work}

Making decisions about where to delineate the boundaries between agent types, and how to classify types that dont fit neatly into the classification scheme, are inherent challenges in creating a classification of groups of individuals. In water resources, agents often belong to more than one of our agent types. For example, water districts in Idaho represent the interests of irrigators, determine the flows of water through the canals in their district, and are governance units as designated by the state (Idaho Department of Water Resources). While this is a common issue, the solution is to determine which of those roles are most important for the particular modeling exercise, and/or explicitly state how the agent is affecting pools and fluxes through specific functions associated with a given type (e.g. they could enforce regulations via their control over the delivery of water). Future work would benefit from empirical studies characterizing individuals within each agent type, much like the AFTs created for land owners in Blanco et al. (2015). These types of empirical studies could elucidate if and how the functional roles of agents within the same type change from one location to another. Further work should strive to identify the frequency and form of information that impact decisions, further improving our understanding of what information is needed as input into ABMs. Development of standard APIs for ABMs would also be beneficial, but will require a community effort, after foundations such as these typologies have been agreed upon.

Any effort to model a CNH system requires careful consideration of how to best operationalize individual and collective decision making. One advantage of an agent-based model is its ability to flexibly incorporate heterogeneity in behavior and decision making. However, this flexibility 
has resulted in a lack of consistency in how decision-making is captured in different models, and inadequate grounding in established theory (Groeneveld et al., 2017). Furthermore, until recently theoretical motivation of model development too often relied exclusively on the rational actor model (Schlüter et al. 2017). One unrealized merit of the AFT approach is that functional types could be defined to capture and represent different theoretical assumptions about human behavior, thereby allowing for an examination of these different theoretical approaches. In constructing our agent typology, we chose not to commit to a particular theoretical approach, but rather to identify and explicate a number of important influences on behavior that apply to all agent types and should likely be considered in model building, including learning from previous experience, information transmission and learning from others, environmental interactions and economic factors.

One synthetic, yet relatively under-appreciated approach to conceptualizing behavior in coupled models is the cultural evolutionary perspective. The process by which certain ideas and beliefs spread at the expense of others (via learning and imitation) is through cultural evolution (Boyd and Richerson, 1985). A broad body of theoretical work in the field of cultural evolution has identified the learning strategies (e.g., imitate the most successful; imitate the majority) that are likely to evolve under environmental uncertainty, and their population-level outcomes (Mesoudi, 2011). The cultural evolutionary perspective thus specifies the social processes that are needed to explicitly model the co-evolutionary dynamics of CNH systems (e.g. adaptation under environmental uncertainty), and therefore could be useful in the field of socio-hydrology, which seeks to specifically understand these co-evolutionary processes (Sivapalan et al., 2012)). Models operationalizing behavior using a cultural evolutionary perspective have had productive impact in the contexts of sustainability (Waring et al. 2015), land-use change (Ellis et al., 2018), environmental management (Baggio and Hillis, 2018), but only recently have scholars explicitly applied cultural evolutionary ideas to a water resources management model (Yu et al., ????). 


\subsection{ABM documentation standards and considerations for creating a water resources ABM}

Documentation of ABMs is imperative for replication and transferability of CNH models. Description of key attributes such as geographic extent and resolution of both social and biophysical components can help in communicating the nature of the questions and model itself. Our water agent types should aid in determining which agents are relevant to the research questions by enabling identification of which agents influence the largest pools and fluxes of water, and which are most important for a specific water quality/quantity problem. The scale of aggregation for agents refers to whether an agent is representing an individual, an organization or institution, and correspondingly determines the degree of heterogeneity needed to describe agent attributes within each functional type. This is an important stage for determining whether a hierarchical structure or other scale-dependent relationship exists between and among the selected agents. Assigning agent attributes then sets the degree of heterogeneity the $\mathrm{ABM}$ is representing, and the range of variability that can occur in their decision-making process. This heterogeneity, captured within the water resource typologies, can then be scaled up to model $\mathrm{CNH}$ systems at regional to continental scales. In this way, a model developed for an individual city or watershed could be expanded to include multiple cities, by simply increasing the spatial extent of the model and the number of agents. Rather than having to redefine how individuals influence water resources, it would only entail defining which stores and river reaches the new agents draw from and return water to.

One challenge with evaluating ABMs (or systems models in general) is the inherent complexity of modeling both social and ecological systems. Given the ad-hoc nature of many ABMs, various protocols and frameworks to improve transparency and replicability of ABMs have been developed by the community Grimm et al., 2010; Müller et al., 2013; Grimm et al., 2014; Wilensky and Rand, 2015; Schmolke et al., 2010). The ODD (Overview, Design concepts, Details) protocol was „reated as a common structure for describing ABMs (Grimm et al., 2006) and updated by Grimm et al. (2010) to decrease ambiguities in the original ODD protocol. They stress the importance of 
standardized descriptions to assure models are described completely and consistently. The need for documenting additional details about human decision-making was highlighted and appended to the ODD by (Müller et al., 2013) to include more details about the empirical or theoretical reasoning behind the choice of decision-making models $(\mathrm{ODD}+\mathrm{D})$. Because the model development process is iterative Grimm et al. (2014) proposed a standard format and terminology for documenting models and improving their transparency, much like a lab or field notebook (TRACE: TRAnsparent and Comprehensive Ecological modeling documentation). Adoption of these protocols can further the culture of good modeling practice such as in the Community Surface Dynamics Modeling System (Hutton et al., 2014, Peckham et al., 2013). The utility of these protocols had already been demonstrated by the CoMSES Network OpenABM Computational Model Library which supports the reproducibility and reuse of over 500 ABMs (comses.net).

\section{Conclusions}

Coupling ABMs with physically based models will become an increasingly important line of inquiry in order to assess how the intersection of climate change, changes in water resource management, and social networks affect social adaptation and its influence on, and feedbacks with, the biophysical system. Describing and using a common set of water resources agent types will expedite model development, simplify integration of models, and potentially increase synthesis of findings across systems. This agent typology will simplify representations of nested, or hierarchical structures that are present in water governance which might be analogous across similar basins. This is particularly useful in regions and circumstances where data characterizing facets of agents is scarce or must be inferred indirectly. Using one set of agent types for water resources ABMs will also result in more transferable models that could be used to capture high resolution dynamics at the regional scale and could be used or expanded upon to further assess integrated food and energy systems.

Our literature review highlights a range of future work for the growing effort to model CNH systems. Empirical work on the variability of reservoir managers biases, governance structures, 
and information flows would help parameterize agents. Balancing the process detail of social and hydrologic flows will continue to be challenging, but requisite to capturing emergent dynamics of our water resources.

\section{Conflict of Interest Statement}

The authors declare that the research was conducted in the absence of any commercial or financial relationships that could be construed as a potential conflict of interest.

\section{Author Contributions}

Conception of creating water resources agents AF and KEK. KEK preformed the literature review and organized the findings; All authors contributed to the development of the agent typologies. KEK wrote the first draft of the manuscript; All authors edited the manuscript.

\section{Funding}

Funding for this work was supported by Idaho EPSCoR (IIA-1301792) and Alejandro Flores' NSF CAREER award (EAR-1352631).

\section{Acknowledgments}

\section{Data Availability Statement}

The datasets generated for this study can be found in HydroShare. Kaiser, K.E., A. Flores, V. Hillis (2018). Literature Review of Water Resources Agent-Based Models, HydroShare, [https://www.hydroshare.org/resource/4294e9cedfca49838c2b191bc6f62260/]. 


\section{References}

[1] Ahmad, S. and Prashar, D. (2010). Evaluating Municipal Water Conservation Policies Using a Dynamic Simulation Model. Water Resources Management 24, 3371-3395. doi: $10.1007 / \mathrm{s} 11269-010-9611-2$

[2] Ahmad, S. and Simonovic, S. P. (2000). System Dynamics Modeling of Reservoir Operations for Flood Management. System Dynamics Modeling of Reservoir Operations for Flood Management 14, 190-198. doi:10.1146/annurev.earth.30.091201.140243

[3] Ahmad, S. and Simonovic, S. P. (2004). Spatial System Dynamics: New Approach for Simulation of Water Resources Systems. Journal of Computing in Civil Engineering 18, 331-340. doi:10.1061/(ASCE)0887-3801(2004)18:4(331)

[4] Akhbari, M. and Grigg, N. S. (2015). Managing water resources conflicts: Modelling behavior in a decision tool. Water Resources Management 29, 5201-5216. doi:10.1007/s11269-015-1113-9

[5] Arneth, A., Brown, C., and Rounsevell, M. D. A. (2014). Global models of human decisionmaking for land-based mitigation and adaptation assessment. Nature Climate Change 4, 550-557. doi:10.1038/nclimate2250

[6] Baggio, J. and Hillis, V. (2018). Managing ecological disturbances: Learning and the structure of social-ecological networks. Environmental Modelling \& Software 109, 32-40. doi:10.1016/j. envsoft.2018.08.002

[7] Bah, A., Touré, I., Le Page, C., Ickowicz, A., and Diop, A. T. (2006). An agent-based model to understand the multiple uses of land and resources around drillings in Sahel. Mathematical and Computer Modelling 44, 513-534. doi:10.1016/j.mcm.2005.02.014

[8] Baietti, A., Kingdom, W., and van Ginneken, M. (2006). Characteristics of Well- Performing Public Water Utilities. Water Supply 8 Sanitation Working Notes 
[9] Bakarji, J., O’Malley, D., and Vesselinov, V. V. (2017). Agent-Based Socio-Hydrological Hybrid Modeling for Water Resource Management. Water Resources Management, 1-18doi: $10.1007 / \mathrm{s} 11269-017-1713-7$

[10] Barbalios, N., Ioannidou, I., Tzionas, P., and Paraskeuopoulos, S. (2013). Behavioural adaptation towards efficient resource sharing under the lack of communication. Journal of Environmental Informatics 21, 119-135. doi:10.3808/jei.201300239

[11] Barthel, R., Janisch, S., Nickel, D., Trifkovic, A., and Horhan, T. (2010). Using the multiactor-approach in GLOWA-danube to simulate decisions for the water supply sector under conditions of global climate change. Water Resources Management 24, 239-275. doi:10.1007/s11269-009-9445-y

[12] Barthel, R., Janisch, S., Schwarz, N., Trifkovic, A., Nickel, D., Schulz, C., et al. (2008). An integrated modelling framework for simulating regional-scale actor responses to global change in the water domain. Environmental Modelling and Software 23, 1095-1121. doi: 10.1016/j.envsoft.2008.02.004

[13] Bates, B., Kundzewicz, Z., Wu, S., and Palutikof, J. (2008). Climate Change and Water (Intergovernmental Panel on Climate Change). doi:10.1016/j.jmb.2010.08.039

[14] Baum, R., Characklis, G. W., and Serre, M. L. (2018). Effects of Geographic Diversification on Risk Pooling to Mitigate Drought-Related Financial Losses for Water Utilities. Water Resources Research , 1-19doi:10.1002/2017WR021468

[15] Becu, N., Perez, P., Walker, A., Barreteau, O., and Le Page, C. (2003). Agent based simulation of a small catchment water management in northern Thailand Description of the CATCHSCAPE model. Ecological Modelling 170, 319-331. doi:10.1016/S0304-3800(03) 00236-9

[16] Bellaubi, F. and Pahl-Wostl, C. (2017). Corruption risks, management practices and performance in Water Service Delivery in Kenya and Ghana. Ecology and Society 22, 1-16 
[17] Berger, T., Birner, R., Diaz, J., McCarthy, N., and Wittmer, H. (2007). Capturing the complexity of water uses and water users within a multi-agent framework. Integrated Assessment of Water Resources and Global Change: A North-South Analysis , 129-148doi: 10.1007/978-1-4020-5591-1-9

[18] Berglund, E. Z. (2012). Using Agent-Based Modeling for Water Resources Planning and Management. Journal of Water and Resources Planning Management 141, 1-17. doi: 10.1061/(ASCE)WR.1943-5452.0000544.

[19] Bithell, M. and Brasington, J. (2009). Coupling agent-based models of subsistence farming with individual-based forest models and dynamic models of water distribution. Environmental Modelling and Software 24, 173-190. doi:10.1016/j.envsoft.2008.06.016

[20] Blanco, V., Brown, C., Holzhauer, S., Vulturius, G., and Rounsevell, M. D. (2017). The importance of socio-ecological system dynamics in understanding adaptation to global change in the forestry sector. Journal of Environmental Management 196, 36-47. doi:10.1016/j. jenvman.2017.02.066

[21] Blanco, V., Brown, C., and Rounsevell, M. (2015). Characterising forest owners through their objectives, attributes and management strategies. European Journal of Forest Research 134, 1027-1041. doi:10.1007/s10342-015-0907-x

[22] Blanco, V., Holzhauer, S., Brown, C., Lagergren, F., Vulturius, G., Lindeskog, M., et al. (2017). The effect of forest owner decision-making, climatic change and societal demands on land-use change and ecosystem service provision in Sweden. Ecosystem Services 23, 174-208. doi:10.1016/j.ecoser.2016.12.003

[23] Boyd, R. and Richerson, P. (1985). Culture and the Evolutionary Proces (University of Chicago Press)

[24] BPA, B. P. A., US BOR, U. B. o. R., and USACE, U. A. C. o. E. (2001). The Columbia 
River System Inside Story. Tech. rep., Bonneville Power Administration, U.S. Bureau of Reclamation, U.S. Army Corps of Engineers

[25] Cai, J. and Xiong, H. (2017). An agent-based simulation of cooperation in the use of irrigation systems. Complex Adaptive Systems Modeling 5, 9. doi:10.1186/s40294-017-0047-x

[26] Cai, X., Yang, Y.-C. E., Zhao, J., and Ringler, C. (2011). Can Water Allocation in the Yellow River Basin Be Improved? Insights From a Multi-agent System Model. Tech. Rep. IFPRI Discussion Paper 01117, International Food Policy Research Institute

[27] Chaffin, B. C., Garmestani, A. S., Gosnell, H., and Craig, R. K. (2016). Institutional networks and adaptive water governance in the Klamath River Basin, USA. Environmental Science $\mathcal{G}$ Policy 57, 112-121. doi:10.1016/j.envsci.2015.11.008

[28] Crosman, K. (2013). The roles of non-governmental organizations in marine conservation. Ph.D. thesis, University of Michigan

[29] Dadson, S., Hall, J. W., Garrick, D., Sadoff, C., Grey, D., and Whittington, D. (2017). Water security, risk, and economic growth: Insights from a dynamical systems model. Water Resources Research , 6425-6438doi:10.1002/2017WR020640

[30] Dalolu, I., Nassauer, J. I., Riolo, R. L., and Scavia, D. (2014). Development of a farmer typology of agricultural conservation behavior in the american corn belt. Agricultural Systems 129, 93-102. doi:10.1016/j.agsy.2014.05.007

[31] Di Baldassarre, G., Kooy, M., Kemerink, J. S., and Brandimarte, L. (2013). Towards understanding the dynamic behaviour of floodplains as human-water systems. Hydrology and Earth System Sciences 17, 3235-3244. doi:10.5194/hess-17-3235-2013

[32] Di Baldassarre, G., Viglione, A., Carr, G., Kuil, L., Salinas, J. L., and Blöschl, G. (2013). Socio-hydrology: Conceptualising human-flood interactions. Hydrology and Earth System Sciences 17, 3295-3303. doi:10.5194/hess-17-3295-2013 
[33] Dieter, C., Maupin, M., Caldwell, R., Harris, M., Ivahnenko, T., Lovelace, J., et al. (2018). Estimated Use of Water in the United States in 2015. Tech. rep., U.S. Geological Survey

[34] Ding, N., Erfani, R., Mokhtar, H., and Erfani, T. (2016). Agent Based Modelling for Water Resource Allocation in the Transboundary Nile River. Water 8, 139. doi:10.3390/w8040139

[35] Dubbelboer, J., Nikolic, J., Jenkins, K., Hall, J. (2017). An Agent-Based Model of Flood Risk and Insurance. Journal of Artificial Societies and Social Simulation doi:10.18564/jasss.3135

[36] Elhay, S., Piller, O., Deuerlein, J., and Simpson, A. R. (2016). A Robust, Rapidly Convergent Method That Solves the Water Distribution Equations for Pressure-Dependent Models. Journal of Water Resources Planning and Management 142, 1-12. doi:10.1061/(ASCE)WR

[37] Ellis, E. C., Magliocca, N. R., Stevens, C. J., and Fuller, D. Q. (2018). Evolving the Anthropocene: linking multi-level selection with long-term socialecological change. Sustainability Science 13, 119-128. doi:10.1007/s11625-017-0513-6

[38] Espinasse, B. (2005). Multiagent Modeling and Simulation of Hydraulic Management of the Camargue. Simulation 81, 201-221. doi:10.1177/0037549705053171

[39] Esteve, P., Varela-Ortega, C., Blanco-Gutiérrez, I., and Downing, T. E. (2015). A hydroeconomic model for the assessment of climate change impacts and adaptation in irrigated agriculture. Ecological Economics 120, 49-58. doi:10.1016/j.ecolecon.2015.09.017

[40] Farhadi, S., Nikoo, M. R., Rakhshandehroo, G. R., Akhbari, M., and Alizadeh, M. R. (2016). An agent-based-nash modeling framework for sustainable groundwater management: A case study. Agricultural Water Management 177, 348-358. doi:10.1016/j.agwat.2016.08.018

[41] Farolfi, S., Müller, J. P., and Bonté, B. (2010). An iterative construction of multi-agent models to represent water supply and demand dynamics at the catchment level. Environmental Modelling and Software 25, 1130-1148. doi:10.1016/j.envsoft.2010.03.018 
[42] Feuillette, S., Bousquet, F., and Le Goulven, P. (2003). SINUSE: A multi-agent model to negotiate water demand management on a free access water table. Environmental Modelling and Software 18, 413-427. doi:10.1016/S1364-8152(03)00006-9

[43] Fontaine, C. M. and Rounsevell, M. D. A. (2009). An Agent-based approach to model future residential pressure on a regional landscape. Landscape Ecology 24, 1237-1254. doi: 10.1007/s10980-009-9378-0

[44] George, B., Malano, H., Davidson, B., Hellegers, P., Bharati, L., and Massuel, S. (2011). An integrated hydro-economic modelling framework to evaluate water allocation strategies I: Model development. Agricultural Water Management 98, 733-746. doi:10.1016/j.agwat.2010.12.004

[45] Ghosh, S., Cobourn, K. M., and Elbakidze, L. (2014). Water banking, conjunctive administration, and drought: The interaction of water markets and prior appropriation in southeastern Idaho. Water Resources Research 50, 6927-6949. doi:10.1002/2014WR015572

[46] Giuliani, M. and Castelletti, A. (2013). Assessing the value of cooperation and information exchange in large water resources systems by agent-based optimization. Water Resources Research 49, 3912-3926. doi:10.1002/wrcr.20287

[47] Griffin, R. C. (2012). The Origins and Ideals of Water Resource Economics in the United States. Annual Review of Resource Economics 4, 353-377. doi:10.1146/ annurev-resource-110811-114517

[48] Grimm, V., Augusiak, J., Focks, A., Frank, B. M., Gabsi, F., Johnston, A. S. A., et al. (2014). Towards better modelling and decision support: Documenting model development, testing, and analysis using TRACE. Ecological Modelling 280, 129-139. doi:10.1016/j.ecolmodel.2014. 01.018

[49] Grimm, V., Berger, U., Bastiansen, F., Eliassen, S., Ginot, V., Giske, J., et al. (2006). A standard protocol for describing individual-based and agent-based models. Ecological Modelling 198, 115-126. doi:10.1016/j.ecolmodel.2006.04.023 
[50] Grimm, V., Berger, U., DeAngelis, D. L., Polhill, J. G., Giske, J., and Railsback, S. F. (2010). The ODD protocol: A review and first update. Ecological Modelling 221, 2760-2768. doi:10.1016/j.ecolmodel.2010.08.019

[51] Groeneveld, J., Müller, B., Buchmann, C., Dressler, G., Guo, C., Hase, N., et al. (2017). Theoretical foundations of human decision-making in agent-based land use models a review. Environmental Modelling ES Software 87, 39-48. doi:10.1016/j.envsoft.2016.10.008

[52] Gunda, T., Turner, B. L., and Tidwell, V. C. (2018). The Influential Role of Sociocultural Feedbacks on Community-Managed Irrigation System Behaviors During Times of Water Stress. Water Resources Research , 1-18doi:10.1002/2017WR021223

[53] Harou, J., Pulido-Velazquez, M., Rosenberg, D. E., Medellin-Azuara, J., Lund, J., and Howitt, R. (2009). Hydro-Economic Models: Concepts, Design, Applications, and Future Prospects. Journal of Hydrology 375, 627-643. doi:10.1016/j.jhydrol.2009.06.037.This

[54] [Dataset] Holtz, G. and Pahl-wostl, C. (2005). Guadiana land-use change model ODD protocol

[55] Holtz, G. and Pahl-Wostl, C. (2012). An agent-based model of groundwater over-exploitation in the Upper Guadiana, Spain. Regional Environmental Change 12, 95-121. doi:10.1007/ s10113-011-0238-5

[56] Huang, Z., Hejazi, M., Li, X., Tang, Q., Vernon, C., Leng, G., et al. (2018). Reconstruction of global gridded monthly sectoral water withdrawals for 1971-2010 and analysis of their spatiotemporal patterns. Hydrology and Earth System Sciences 22, 2117-2133. doi:10.5194/ hess-22-2117-2018

[57] Huber-Stearns, H. R., Bennett, D. E., Posner, S., Richards, R. C., Fair, J. H., Cousins, S. J., et al. (2017). Social-ecological enabling conditions for payments for ecosystem services. Ecology and Society 22. doi:10.5751/ES-08979-220118 
[58] Huntington, T. G., Weiskel, P. K., Wolock, D. M., and McCabe, G. J. (2018). A new indicator framework for quantifying the intensity of the terrestrial water cycle. Journal of Hydrology 559, 361-372. doi:10.1016/j.jhydrol.2018.02.048

[59] [Dataset] Hutton, E. W. H., Piper, M. D., Peckham, S. D., Overeem, I., Kettner, A. J., and Syvitski, J. P. M. (2014). Building Sustainable Software - The CSDMS Approach

[60] [Dataset] IDWR (2018). Idaho Department of Water Resources Web Page

[61] Islami, I. (2017). Modeling Socio-Ecological Structure of Local Communities Participation for Managing Livestock Drinking Water Using the Agent-Based Approach. Applied Ecology and Environmental Research 15, 1173-1192. doi:10.15666/aeer/1503\{\-\}11731192

[62] Jenkins, K., Surminski, S., Hall, J., and Crick, F. (2017). Assessing surface water flood risk and management strategies under future climate change: Insights from an Agent-Based Model. Science of the Total Environment 595, 159-168. doi:10.1016/j.scitotenv.2017.03.242

[63] Jeuland, M., Baker, J., Bartlett, R., and Lacombe, G. (2014). The costs of uncoordinated infrastructure management in multi-reservoir river basins. Environmental Research Letters 9, 105006. doi:10.1088/1748-9326/9/10/105006

[64] Karali, E., Brunner, B., Doherty, R., Hersperger, A. M., and Rounsevell, M. D. A. (2013). The Effect of Farmer Attitudes and Objectives on the Heterogeneity of Farm Attributes and Management in Switzerland. Human Ecology 41, 915-926. doi:10.1007/s10745-013-9612-x

[65] Kenbeek, S., Bone, C., and Moseley, C. (2016). A network modeling approach to policy implementation in natural resource management agencies. Computers, Environment and Urban Systems 57, 155-177. doi:10.1016/j.compenvurbsys.2016.02.003

[66] Khan, H. F., Yang, Y.-C. E., and Ringler, C. (2017). Heterogeneity in Riverine Ecosystem Service Perceptions : Insights for Water- decision Processes in Transboundary Rivers. IFPRI Discussion Paper , 1-24 
[67] Kimmell, T. and Veil, J. (2009). Impact of Drought on U . S . Steam Electric Power Plant Cooling Water Intakes and Related Water Resource Management Issues. Tech. rep., U.S. Department of Energy, National Energy Technology Laboratory

[68] King, L. M., Simonovic, S. P., and Hartford, D. N. (2017). Using system dynamics simulation for assessment of hydropower system safety. Water Resources Research 53, 7148-7174. doi:10.1002/2017WR020834

[69] Kock, B. (2008). Agent-based models of socio-hydrological systems for exploring the institutional dynamics of water resources conflict. Ph.D. thesis, MIT

[70] Koutiva, I. and Makropoulos, C. (2016). Modelling domestic water demand: An agent based approach. Environmental Modelling \& Software 79, 35-54. doi:10.1016/j.envsoft.2016.01.005

[71] Kuil, L., Evans, T., Mccord, P. F., Salinas, J. L., and Blöschl, G. (2018). Exploring the influence of smallholders' perceptions regarding water availability on crop choice and water allocation through socio - hydrological modelling. Water Resources Research , 1-25doi: 10.1002/2017WR021420

[72] Ma, L., Ahuja, L. R., and Malone, R. W. (2007). Systems Modeling For Soil and Water Research and Management; current status and needs for the 21st Century. Transactions Of The Asabe 50, 1705-1713

[73] Mavrommati, G., Borsuk, M., and Howarth, R. (2016). A novel deliberative multicriteria evaluation approach to ecosystem service. Ecology and Society 22

[74] Mckinney, J. C. (1950). Social Forces Scientific Sociological Analysis. Sociological Analysis 28, $235-240$

[75] Mesoudi, A. (2011). Cultural evolution: How Darwinian theory can explain human culture and synthesize the social sciences (Chicago and London: University of Chicago Press) 
[76] Michelsen, A. M., Taylor, R. G., Huffaker, R. G., and McGuckin, J. T. (1999). Emerging Agricultural Water Conservation Price Incentives. Journal of Agricultural and Resource Economics 24, 222-238

[77] Mirchi, A., Madani, K., Watkins, D., and Ahmad, S. (2012). Synthesis of System Dynamics Tools for Holistic Conceptualization of Water Resources Problems. Water Resources Management 26, 2421-2442. doi:10.1007/s11269-012-0024-2

[78] Müller, B., Bohn, F., Dreßler, G., Groeneveld, J., Klassert, C., Martin, R., et al. (2013). Describing human decisions in agent-based models - ODD+D, an extension of the ODD protocol. Environmental Modelling and Software 48, 37-48. doi:10.1016/j.envsoft.2013.06.003

[79] Mulligan, K. B., Brown, C., Yang, Y.-C. E., and Ahlfeld, D. P. (2014). Assessing groundwater policy with coupled economic-groundwater hydrologic modeling. Water Resources Research 50, 4149-4162. doi:10.1002/2013WR015173

[80] Newig, J., Gunther, D., and Pahl-Wostl, C. (2010). Synapses in the Network: Learning in Governance Networks in the Context of Environmental Management. Ecology an 15. doi:10.1197/jamia.M2385

[81] Nikolic, V. V. and Simonovic, S. P. (2015). Multi-method Modeling Framework for Support of Integrated Water Resources Management. Environmental Processes 2, 461-483. doi: $10.1007 / \mathrm{s} 40710-015-0082-6$

[82] Noël, P. H. and Cai, X. (2017). On the role of individuals in models of coupled human and natural systems: Lessons from a case study in the Republican River Basin. Environmental Modelling and Software 92, 1-16. doi:10.1016/j.envsoft.2017.02.010

[83] Ostrom, E. (2009). A general framework for analyzing sustainability of. Science 325, 419-422. doi:10.1126/science.1172133

[84] Overeem, I., Berlin, M. M., and Syvitski, J. P. M. (2013). Strategies for integrated modeling: 
The community surface dynamics modeling system example. Environmental Modelling and Software 39, 314-321. doi:10.1016/j.envsoft.2012.01.012

[85] Patterson, L. A. and Doyle, M. W. (2018). A Nationwide Analysis of U.S. Army Corps of Engineers Reservoir Performance in Meeting Operational Targets. JAWRA Journal of the American Water Resources Association 27708, 1-22. doi:10.1111/1752-1688.12622

[86] Peckham, S. D., Hutton, E. W., and Norris, B. (2013). A component-based approach to integrated modeling in the geosciences: The design of CSDMS. Computers and Geosciences 53, 3-12. doi:10.1016/j.cageo.2012.04.002

[87] Petak, W. J. (1980). Environmental planning and management: The need for an integrative perspective. Environmental Management Environmental Management : An International Journal for Decision Makers, Scientists and Environmental Auditors 4, 287-295

[88] Rathwell, K. J. and Peterson, G. D. (2012). Connecting social networks with ecosystem services for watershed governance: A social-ecological network perspective highlights the critical role of bridging organizations. Ecology and Society 17. doi:10.5751/ES-04810-170224

[89] Rehan, R., Knight, M. A., Unger, A. J., and Haas, C. T. (2013). Development of a system dynamics model for financially sustainable management of municipal watermain networks. Water Research 47, 7184-7205. doi:10.1016/j.watres.2013.09.061

[90] Rounsevell, M. D. A., Robinson, D. T., and Murray-Rust, D. (2012). From actors to agents in socio-ecological systems models. Philosophical Transactions of the Royal Society B: Biological Sciences 367, 259-269. doi:10.1098/rstb.2011.0187

[91] Saqalli, M., Thiriot, S., and Amblard, F. (2010). Investigating Social Conflicts Linked to Water Resources through Agent-Based Modelling. NATO Science for Peace and Security Series - E: Human and Societal Dynamics 75, 142-157 
[92] Schenk, C., Roquier, B., Soutter, M., and Mermoud, A. (2009). A system model for water management. Environmental Management 43, 458-469. doi:10.1007/s00267-008-9254-8

[93] Schlüter, M., Baeza, A., Dressler, G., Frank, K., Groeneveld, J., Jager, W., et al. (2017). A framework for mapping and comparing behavioural theories in models of social-ecological systems. Ecological Economics 131, 21-35. doi:10.1016/j.ecolecon.2016.08.008

[94] Schlüter, M., Leslie, H., and Levin, S. (2009). Managing water-use trade-offs in a semi-arid river delta to sustain multiple ecosystem services: A modeling approach. Ecological Research 24, 491-503. doi:10.1007/s11284-008-0576-z

[95] Schmolke, A., Thorbek, P., DeAngelis, D. L., and Grimm, V. (2010). Ecological models supporting environmental decision making: A strategy for the future. Trends in Ecology and Evolution 25, 479-486. doi:10.1016/j.tree.2010.05.001

[96] Sehlke, G. and Jacobson, J. (2005). System dynamics modeling of transboundary systems: The river basin model. Ground Water 43, 722-730. doi:10.1111/j.1745-6584.2005.00065.x

[97] Serrano-Tovar, T. and Giampietro, M. (2014). Multi-scale integrated analysis of rural Laos: Studying metabolic patterns of land uses across different levels and scales. Land Use Policy 36, 155-170. doi:10.1016/j.landusepol.2013.08.003

[98] Shafiee, M. E. and Berglund, E. Z. (2017). Complex Adaptive Systems Framework to Simulate the Performance of Hydrant Flushing Rules and Broadcasts during a Water Distribution System Contamination Event. Journal of Water Resources Planning and Management 143, 04017001. doi:10.1061/(ASCE)WR.1943-5452.0000744

[99] Sivapalan, M. and Blöschl, G. (2015). Time scale interactions and the coevolution of humans and water. Water Resources Research 51, 6988-7022. doi:10.1002/2015WR017896

[100] Sivapalan, M., Konar, M., Srinivasan, V., Chhatre, A., Wutich, A., Scott, C. A., et al. (2014). 
Socio-hydrology : Use-inspired water sustainability science for the Anthropocene. Earth's Future 2, 225-230. doi:10.1002/2013EF000164.Received

[101] Sivapalan, M., Savenije, H. H. G., and Blöschl, G. (2012). Socio-hydrology: A new science of people and water. Hydrological Processes 26, 1270-1276. doi:10.1002/hyp.8426

[102] Soboll, A., Elbers, M., Barthel, R., Schmude, J., Ernst, A., and Ziller, R. (2011). Integrated regional modelling and scenario development to evaluate future water demand under global change conditions. Mitigation and Adaptation Strategies for Global Change 16, 477-498. doi:10.1007/s11027-010-9274-6

[103] Souza Filho, F. A., Lall, U., and Porto, R. L. L. (2008). Role of price and enforcement in water allocation: Insights from Game Theory. Water Resources Research 44, 1-16. doi: 10.1029/2007WR006163

[104] Talbot, C. (2009). Book Review: Organising and disorganising - A dynamic and non-linear theory of institutional emergence and its implications by Micheal Thompson. Organization Studies 30, 909-912. doi:10.1177/0170840609344000

[105] Thoyer, S., Morardet, S., Rio, P., Simon, L., Goodhue, R., and Rausser, G. (2001). A bargaining model to simulate negotiations between water users. Jasss 4

[106] Tidwell, V. C., Kobos, P. H., Malczynski, L. A., Klise, G., and Castillo, C. R. (2012). Exploring the Water-Thermoelectric Power Nexus. Journal of Water Resources Planning and Management 139, 554-564. doi:10.1061/(ASCE)WR.1943-5452

[107] Tidwell, V. C., Malczynski, L. A., Kobos, P. H., Klise, G. T., and Shuster, E. (2013). Potential impacts of electric power production utilizing natural gas, renewables and carbon capture and sequestration on U.S. freshwater resources. Environmental Science and Technology 47, 8940-8947. doi:10.1021/es3052284

[108] Tidwell, V. C., Salerno, R. M., Passell, H. D., Larson, K. L., Kalinina, E., Wolf, A. T., et al. 
(2001). Integrating Monitoring and Decision Modeling Within a Cooperative Framework : Promoting Transboundary Water Management and Avoiding Regional Conflict. International Security doi:10.2172/780302

[109] [Dataset] US Army Corps of Engineers (1985). Water Control Manual fo Boise River Reservoirs. doi:10.15713/ins.mmj.3

[110] US Department of Energy (2014). The Water Energy Nexus: Challenges and Opportunities. Report , 238doi:10.1504/IJW.2008.018144

[111] Valbuena, D., Verburg, P. H., and Bregt, A. K. (2008). A method to define a typology for agent-based analysis in regional land-use research. Agriculture, Ecosystems and Environment 128, 27-36. doi:10.1016/j.agee.2008.04.015

[112] Van Emmerik, T. H., Li, Z., Sivapalan, M., Pande, S., Kandasamy, J., Savenije, H. H., et al. (2014). Socio-hydrologic modeling to understand and mediate the competition for water between agriculture development and environmental health: Murrumbidgee River basin, Australia. Hydrology and Earth System Sciences 18, 4239-4259. doi:10.5194/hess-18-4239-2014

[113] Van Oel, P. R., Krol, M. S., and Hoekstra, A. Y. (2012). Application of multi-agent simulation to evaluate the influence of reservoir operation strategies on the distribution of water availability in the semi-arid Jaguaribe basin, Brazil. Physics and Chemistry of the Earth 47-48, 173-181. doi:10.1016/j.pce.2011.07.051

[114] Van Oel, P. R., Krol, M. S., Hoekstra, A. Y., and Taddei, R. R. (2010). Feedback mechanisms between water availability and water use in a semi-arid river basin: A spatially explicit multi-agent simulation approach. Environmental Modelling and Software 25, 433-443. doi: 10.1016/j.envsoft.2009.10.018

[115] Viglione, A., Di Baldassarre, G., Brandimarte, L., Kuil, L., Carr, G., Salinas, J. L., et al. (2014). Insights from socio-hydrology modelling on dealing with flood risk - Roles of collective 
memory, risk-taking attitude and trust. Journal of Hydrology 518, 71-82. doi:10.1016/j.jhydrol. 2014.01.018

[116] Waring, T., Kline, M., Brooks, J., Goff, S., Gowdy, J., Janssen, M., et al. (2015). A multilevel evolutionary framework for sustainability analysis. Ecology and Society 20. doi: 10.5751/ES-07634-200234

[117] Wilensky, U. and Rand, W. (2015). An introduction to agent-based modeling: modeling natural, social, and engineered complex systems with NetLogo (Cambridge, UK: MIT Press)

[118] Woyessa, Y., Welderufael, W., Kinyua, J., Kundhlande, G., and Tsumake, O. (2011). LandWater Linkages : Agent-Based Modelling of Land Use and Its Impact on Water Resources. Tech. Rep. Report 1753, Water Research Commission

[119] Wurbs, R. A. (2005). Modeling river/reservoir system management, water allocation, and supply reliability. Journal of Hydrology 300, 100-113. doi:10.1016/j.jhydrol.2004.06.003

[120] Yates, D., Sieber, J., Purkey, D., and Huber-Lee, A. (2005). WEAP21 - A Demand-, Priority, and Preference-Driven Water Planning Model. Part 1: Model Characteristics. Water International 30, 487-500

[121] Yu, D. J., Chang, H., Davis, T., Hillis, V., Martson, L., Oh, W., et al. (????). From PlaceBased Modeling Toward General Theories of Sociohydrology: Lessons from Social-ecological Systems (in Review). Water Resources Research

[122] Yuan, C., Liu, L., Ye, J., Ren, G., Zhuo, D., and Qi, X. (2017). Assessing the effects of rural livelihood transition on non-point source pollution: a coupled ABMIECM model. Environmental Science and Pollution Research 24, 12899-12917. doi:10.1007/s11356-017-8812-0

[123] Zagona, E. A., Fulp, T. J., Shane, R., Magee, T., and Goranflo, H. M. (2001). Riverware: a Generalized Tool for Complex Reservoir System Modeling1. JAWRA Journal of the American Water Resources Association 37, 913-929. doi:10.1111/j.1752-1688.2001.tb05522.x 
${ }_{1119}$ Tables
[124] Zellner, M. L. (2007). Generating policies for sustainable water use in complex scenarios: An integrated land-use and water-use model of Monroe County, Michigan. Environment and Planning B: Urban Analytics and City Science 34, 664-686. doi:10.1068/b32152 
Table 1: Common modeling approaches in coupled natural human systems, and associated benefits and limitations.

\begin{tabular}{|c|c|c|}
\hline Approach & Benefits & Limitations \\
\hline System Dynamics Models & $\begin{array}{l}\text { Capture complex and nonlinear feedbacks and } \\
\text { relationships }\end{array}$ & $\begin{array}{l}\text { Simplification of system components, where some } \\
\text { features might have greater fidelity to certain } \\
\text { processes than others. }\end{array}$ \\
\hline Hydro-economic models & $\begin{array}{l}\text { Water demand is evaluated based on value, and } \\
\text { opportunity costs can be assessed over time. Of- } \\
\text { ten use high fidelity hydrologic and economic } \\
\text { models that capture important (spatially dis- } \\
\text { tributed) system processes. }\end{array}$ & $\begin{array}{l}\text { Decision-making is often based on complete in- } \\
\text { formation and rational choice (e.g. net benefit } \\
\text { maximization), social structures are not included. } \\
\text { Heterogeneity among agents is not easily repre- } \\
\text { sented, and as such, actions of individual agents } \\
\text { cannot be easily replicated (53: } 47)\end{array}$ \\
\hline Socio-hydrology & $\begin{array}{l}\text { Seek to capture how hydrologic and social dy- } \\
\text { namics influence each other and evolve over time } \\
(101.100) \text {. Hydrologic processes are well cap- } \\
\text { tured by physically based models. }\end{array}$ & $\begin{array}{l}\text { Mismatch in the timescale of environmental man- } \\
\text { agement versus scales of the processes being man- } \\
\text { aged }(99) \text {. Complex social dynamics are some- } \\
\text { times represented by a single parameter }(\underline{32)} \text {, but } \\
\text { recent papers highlight the ability to create truly } \\
\text { coupled models such as in (52, } 71)\end{array}$ \\
\hline Agent Based Models & $\begin{array}{l}\text { Can explicitly incorporate complex human dy- } \\
\text { namics motivated by social theory }(117) \text {. Can } \\
\text { represent dynamic interactions between humans } \\
\text { and the environment. }\end{array}$ & $\begin{array}{l}\text { Local specificity of models makes comparison of } \\
\text { findings challenging. }\end{array}$ \\
\hline Agent typologies & $\begin{array}{l}\text { Categorizes the predominant functional roles of } \\
\text { individuals in the system, thereby standardizing } \\
\text { the possible input/output variables an agent can } \\
\text { influence. }\end{array}$ & $\begin{array}{l}\text { Oversimplification of the variability within the } \\
\text { population, sub-classification of AFTs might be } \\
\text { necessary in some contexts. }\end{array}$ \\
\hline Agent Functional Types & $\begin{array}{l}\text { Characterizes the heterogeneity within a given } \\
\text { agent type, allowing for variability in decision } \\
\text { making strategies, goals and preferences }(21) \text {. } \\
\text { Can also simplify scaling to larger extents and } \\
\text { incorporating greater number of agents (5). }\end{array}$ & $\begin{array}{l}\text { Creating these might require larger amounts of } \\
\text { data, or expert knowledge that can sufficiently } \\
\text { characterize the variability, while being general } \\
\text { enough to be applied to large geographic extents } \\
(90) \text {. }\end{array}$ \\
\hline
\end{tabular}


Table 2: Water resources agent types, roles and associated citations. Roles identify the activities the agents perform.

\begin{tabular}{|c|c|c|}
\hline Agent & Roles & Citations \\
\hline Agriculture & $\begin{array}{l}\text { Water demand } \\
\text { Water distribution } \\
\text { Groundwater banking } \\
\text { Conservation practices } \\
\text { Discharge water } \\
\text { Negotiation } \\
\text { Landuse }\end{array}$ & $\begin{array}{l}82 ; 124 ; 98 ; 4 ; 15 ; 38 ; 41 ; 42 \\
81 ; 91 ; 103 ; 114 ; 25 ; 94 ; 105 \\
17 ; 15 \\
69 \\
\frac{69}{36} ; 98 \\
124 ; 38 \\
15 ; 38 ; 42 \\
41 ; 55 ; 113 ; 122 ; 61 ; 97 ; 19 ; 69\end{array}$ \\
\hline Regulatory & $\begin{array}{l}\text { Regulations } \\
\text { Infrastructure } \\
\text { Water allocation } \\
\text { Incentives/penalties } \\
\text { Data collection } \\
\text { Communication } \\
\text { Records and settles disputes }\end{array}$ & $\begin{array}{l}82 ; 106 ; 69 ; 4 ; 16 ; 61 ; 105 \\
17 \\
17 ; 4 ; 34 ; 38 ; 91 ; 103 ; 114 \\
106 ; 18 ; 91 ; 103 ; 25 ; 16 ; 61 \\
\frac{18}{9} \\
69 ; 16\end{array}$ \\
\hline Domestic & $\begin{array}{l}\text { Water demand } \\
\text { Conservation practices } \\
\text { Population growth }\end{array}$ & $\begin{array}{l}106 ; 9 ; 124 ; 36 ; 4 ; 12 ; 11 ; 91 ; 16 ; 70 \\
\text { 36; } 12 ; 70 \\
18 ; 124 ; 81\end{array}$ \\
\hline Industrial & $\begin{array}{l}\text { Water demand } \\
\text { Water discharge } \\
\text { Water treatment } \\
\text { Trade water quality permits }\end{array}$ & $\begin{array}{l}124 ; 81 \\
124 ; 4 \\
\frac{18}{18} \\
\end{array}$ \\
\hline Water Utilities & $\begin{array}{l}\text { Water distribution } \\
\text { Water treatment } \\
\text { Water use reduction goals } \\
\text { Water use restrictions } \\
\text { Water extraction } \\
\text { Infrastructure } \\
\text { Enforcement } \\
\text { Communication }\end{array}$ & $\begin{array}{l}12 ; 16 ; 36 \\
12 \\
18 ; 16 \\
136 ; 18 \\
12 ; 81 \\
98 \\
11 ; 36 \\
18 \\
\end{array}$ \\
\hline Interest Groups & $\begin{array}{l}\text { Advocacy } \\
\text { Capacity Building } \\
\text { Social cohesion/influence } \\
\text { Litigation } \\
\text { Outreach } \\
\text { Education } \\
\text { Report Violations }\end{array}$ & $\begin{array}{l}61 ; 105 \\
61 \\
61 ; 4 \\
61 \\
61 \\
61 \\
69 \\
4 ;: 105 \\
\end{array}$ \\
\hline Reservoir Management & $\begin{array}{l}\text { Energy production } \\
\text { Release scheduling }\end{array}$ & $\begin{array}{l}4 ; 46 ; 63 ; 26 ; 46 ; 103 \\
69\end{array}$ \\
\hline Economics & $\begin{array}{l}\text { Insurance } \\
\text { Water Banking }\end{array}$ & $\begin{array}{l}35 ; 62 \\
69\end{array}$ \\
\hline
\end{tabular}


Table 3: Proposed criteria that influence agent decisions, and illustrative examples of associated input/output variables. Each agent may also base their decision on other agents previous behaviors and associated payoffs, while current behaviors and payoffs may also be communicated to specified agents. These input/output variables can then lead to social learning and emergent dynamics that wouldn't be captured without incorporating social influences.

\begin{tabular}{|c|c|c|c|}
\hline Agent & Criteria Influencing Decisions & Input & Output \\
\hline Agricultural & $\begin{array}{l}\text { Profit } \\
\text { History } \\
\text { Technology } \\
\text { Loss Aversion } \\
\text { Social Influence }\end{array}$ & $\begin{array}{l}\text { Streamflow } \\
\text { Market Prices } \\
\text { Forecasted Precipitation }(\mathrm{P}) \text {, } \\
\text { Temperature }(\mathrm{T}) \text {, Snow water } \\
\text { equivalent (SWE) }\end{array}$ & $\begin{array}{l}\text { Irrigation } \\
\text { Return flows } \\
\text { ET }\end{array}$ \\
\hline Regulatory & $\begin{array}{l}\text { Rules \& Regulations } \\
\text { History } \\
\text { Profit } \\
\text { Social Influence }\end{array}$ & $\begin{array}{l}\text { Streamflow } \\
\text { Water quality } \\
\text { Canal stage }\end{array}$ & $\begin{array}{l}\text { Rules \& Regulations } \\
\text { Incentives / Penalties } \\
\text { Communication of } \\
\text { environmental conditions }\end{array}$ \\
\hline Domestic & $\begin{array}{l}\text { Minimize Costs } \\
\text { History } \\
\text { Technology } \\
\text { Social Influence } \\
\end{array}$ & $\begin{array}{l}\text { Air temperature } \\
\text { Precipitation } \\
\text { Water use restrictions }\end{array}$ & $\begin{array}{l}\text { Water use (indoor/outdoor) } \\
\text { ET }\end{array}$ \\
\hline Industrial & $\begin{array}{l}\text { Profit } \\
\text { History } \\
\text { Technology } \\
\text { Social Influence }\end{array}$ & $\begin{array}{l}\text { Inflows } \\
\text { Regulations } \\
\text { Market Values }\end{array}$ & $\begin{array}{l}\text { Outflow } \\
\text { Water quality } \\
\text { Trade/buy water quality permits }\end{array}$ \\
\hline Utilities & $\begin{array}{l}\text { Profit } \\
\text { History } \\
\text { Growth Projections } \\
\text { Technology } \\
\text { Regulations } \\
\end{array}$ & $\begin{array}{l}\text { Water use projections } \\
\text { Precipitation, streamflow and } \\
\text { groundwater withdrawal forecasts }\end{array}$ & Water use restrictions \\
\hline Interest Groups & $\begin{array}{l}\text { Social Capital } \\
\text { Environment } \\
\text { History } \\
\text { Technology }\end{array}$ & $\begin{array}{l}\text { Stakeholder involvement } \\
\text { Data from regulatory agent } \\
\text { (water quality and streamflow) }\end{array}$ & Behavioral Recommendations \\
\hline Reservoir Management & $\begin{array}{l}\text { Operational Targets } \\
\text { Profit } \\
\text { History }\end{array}$ & $\begin{array}{l}\text { Forecasts }(\mathrm{P}, \mathrm{T}, \mathrm{SWE}) \\
\text { Inflow } \\
\text { Operational targets }\end{array}$ & $\begin{array}{l}\text { Reservoir Outflow } \\
\text { Transpiration }\end{array}$ \\
\hline Economic & $\begin{array}{l}\text { Local \& Global Markets } \\
\text { Social Influence }\end{array}$ & $\begin{array}{l}\text { Global Demand } \\
\text { Taxes \& Tariffs } \\
\text { Willingness to pay } \\
\text { Willingness to sell }\end{array}$ & $\begin{array}{l}\text { Commodity prices } \\
\text { Market price of water }\end{array}$ \\
\hline
\end{tabular}




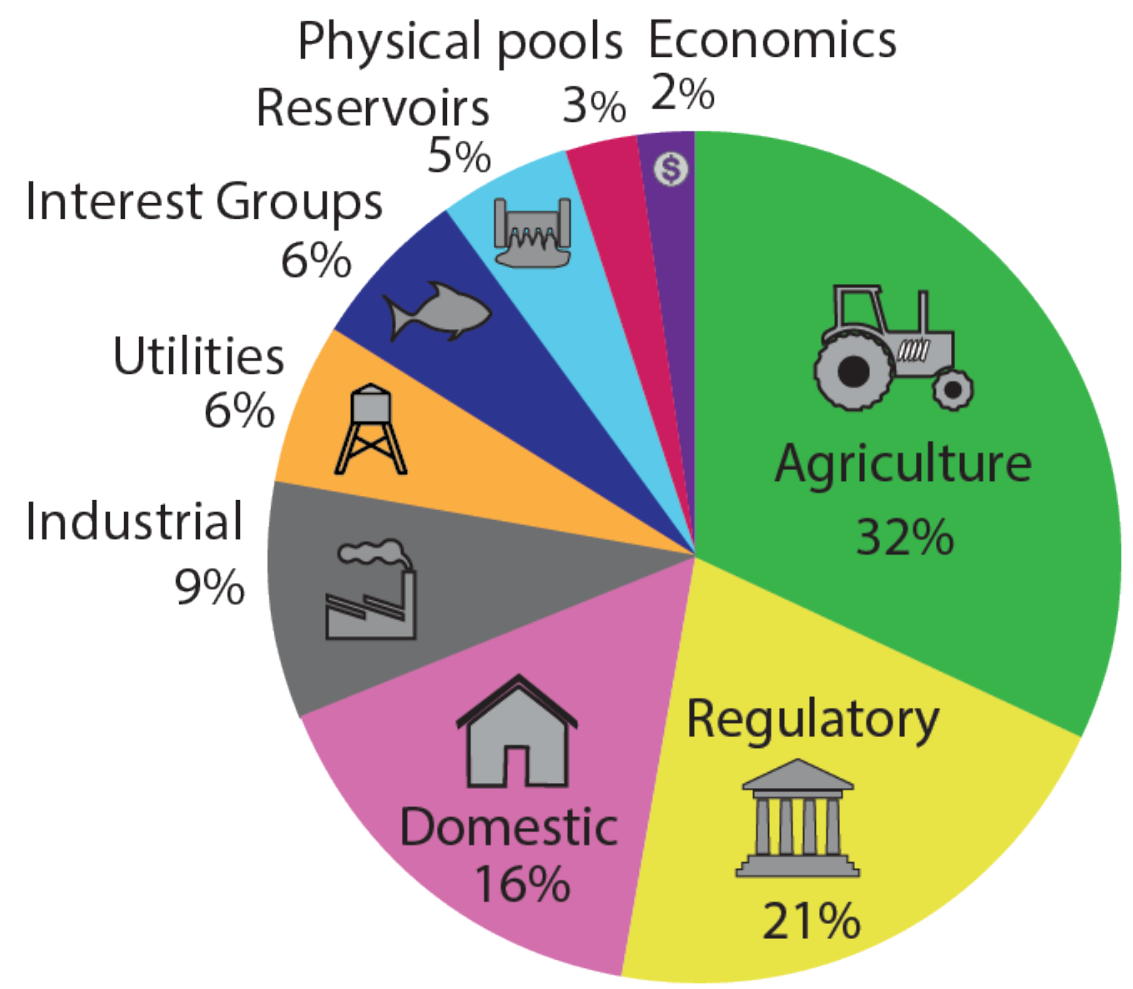

Figure 1: Percentage of each water resources agent present in the reviewed literature. 


\section{Agent Based Model of Water Resources}

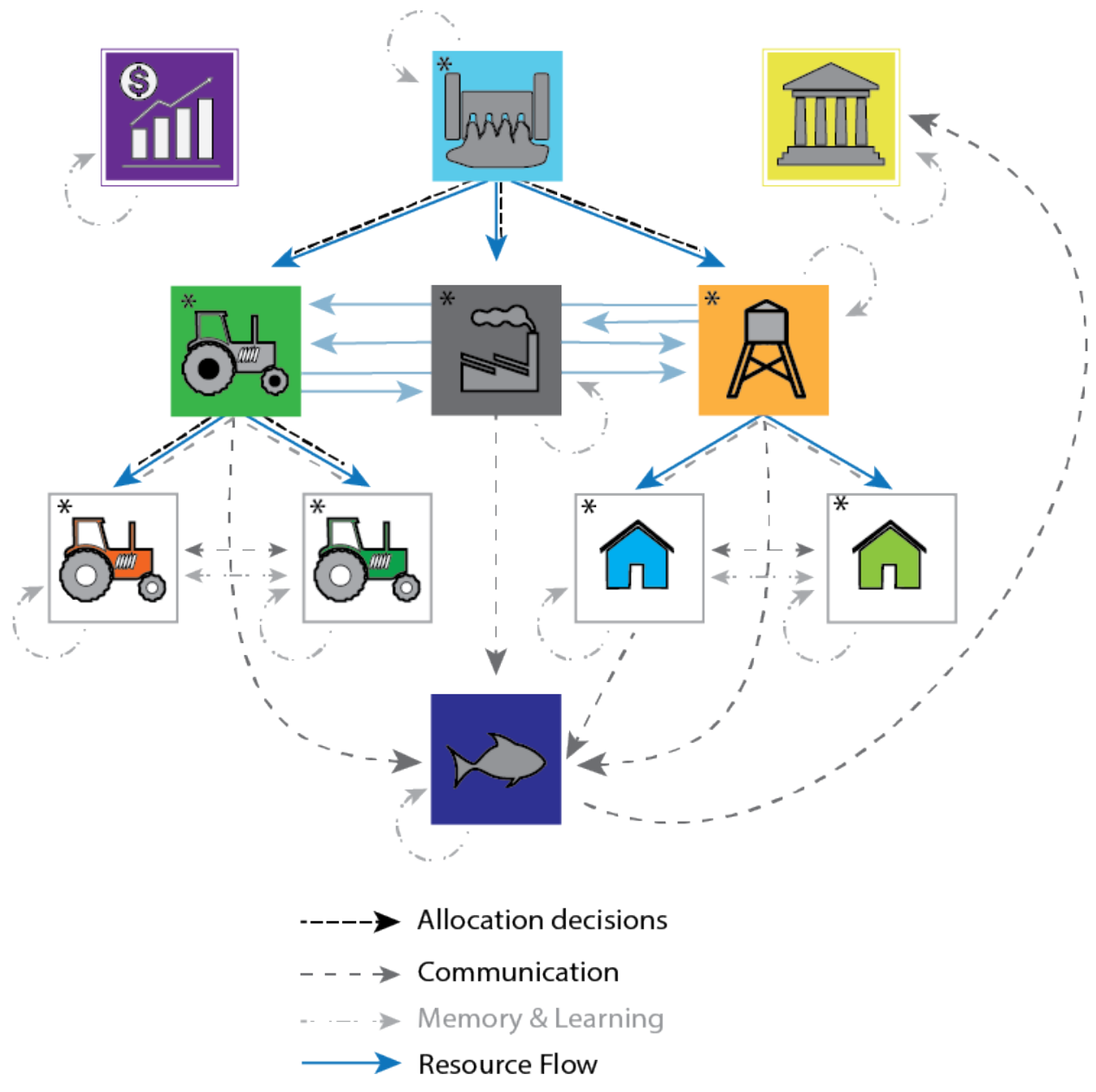

Figure 2: Conceptual inter-relationships between each agent type. Sub-models could replace an individual agent at any node or could dictate decision-making of other agents within the model. * denote agents that directly modify pools and fluxes of water, and the double box around the economic and regulator agent denotes that they have an omnipresent influence on all other agents. 

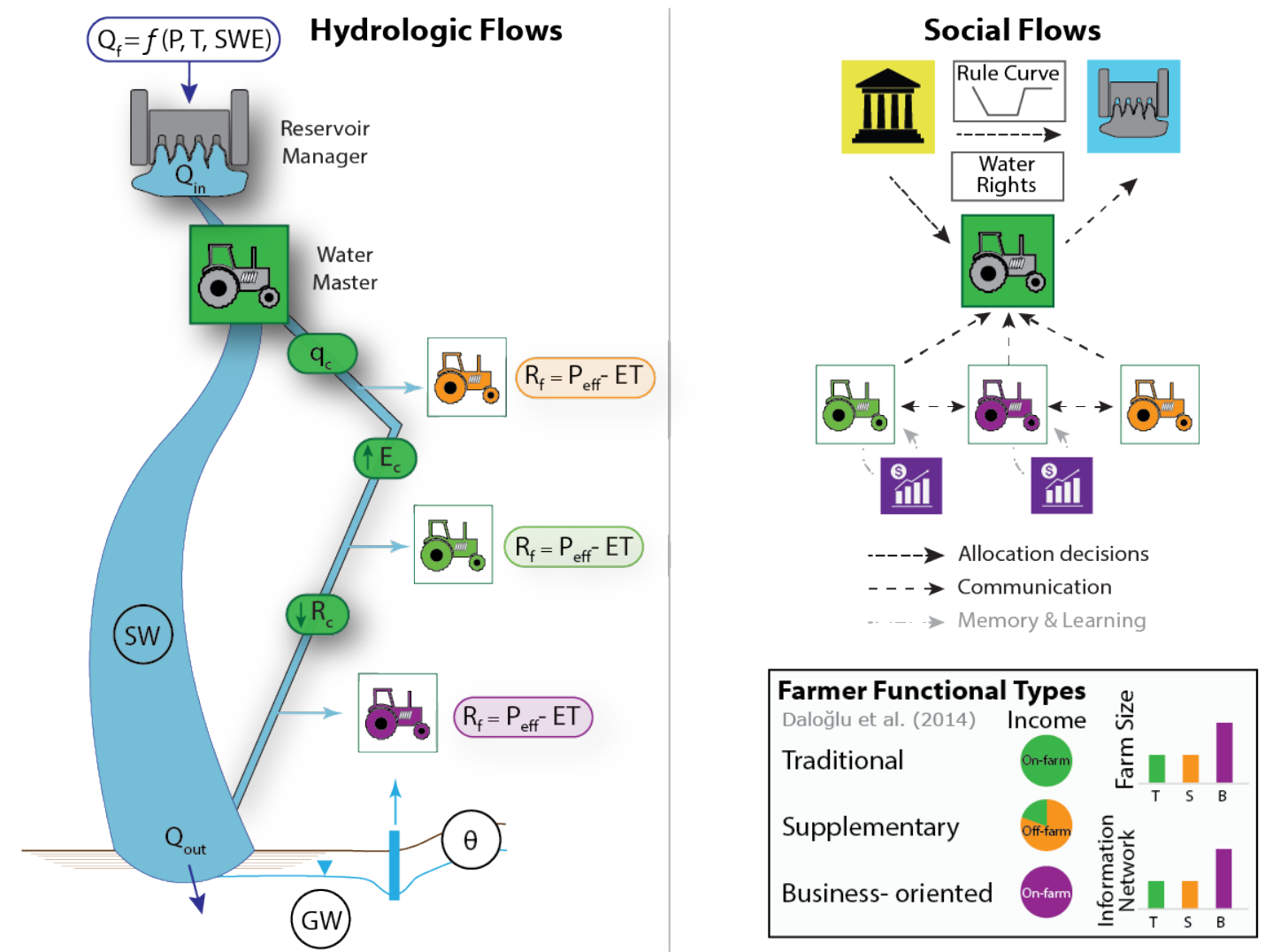

Figure 3: Illustrated example of how agents interact with hydrologic and social flows. The hydrologic flows identify which hydrologic variables each agent affects. The reservoir manager uses forecasts based on precipitation $(P)$, temperature $(T)$, and snow water equivalent $(S W E)$ to make decisions about how much water to release from the reservoir into the river network $\left(Q_{i n}\right)$. The water master then withdraws water from the river to satisfy water rights for irrigators along the associated canal $\left(Q_{\text {canal }}\right)$ which has losses to the shallow aquifer (canal recharge, $R_{c}$ ) and transpiration $\left(E_{c}\right)$. Each farmer then withdraws water from the canal or from their groundwater well, applies it to their field (effective precipitation, $P_{e f f}$ ), and makes decisions about crop cover and irrigation type which determines the amount of evapotranspiration $(E T)$ and recharge $\left(R_{f}\right)$ from their fields. The social flows show how the regulator agent influences reservoir operations as a function of rule curves (operational targets) and water rights. The water master interacts with individual farmers to determine how much water to request from the reservoir manager in the irrigation season. Each individual farmer is making decisions based on previous knowledge, and in this case, some set of economic considerations. The farmer functional types described by Dalolu et al. (30) show how the farmers decisions can be based on a combination of their information network, farm size, and income sources. 